\title{
Post-Translational Modifications of the Paired Box Transcription Factor 7 (Pax7) in Satellite Cells During the Repair of Injured Skeletal Muscle
}

Justin E. Sperringer

West Virginia University

Follow this and additional works at: https://researchrepository.wvu.edu/etd

\section{Recommended Citation}

Sperringer, Justin E., "Post-Translational Modifications of the Paired Box Transcription Factor 7 (Pax7) in Satellite Cells During the Repair of Injured Skeletal Muscle" (2014). Graduate Theses, Dissertations, and Problem Reports. 428.

https://researchrepository.wvu.edu/etd/428

This Thesis is protected by copyright and/or related rights. It has been brought to you by the The Research Repository @ WVU with permission from the rights-holder(s). You are free to use this Thesis in any way that is permitted by the copyright and related rights legislation that applies to your use. For other uses you must obtain permission from the rights-holder(s) directly, unless additional rights are indicated by a Creative Commons license in the record and/ or on the work itself. This Thesis has been accepted for inclusion in WVU Graduate Theses, Dissertations, and Problem Reports collection by an authorized administrator of The Research Repository @ WVU. For more information, please contact researchrepository@mail.wvu.edu. 


\title{
Post-Translational Modifications of the Paired Box Transcription Factor 7 (Pax7) in Satellite Cells During the Repair of Injured Skeletal Muscle
}

Justin E. Sperringer, B.S.

Thesis submitted to the School of Medicine, Division of Exercise Physiology at West Virginia University in partial fulfillment of the requirements for the degree of Master of Science in Exercise Physiology

\section{Committee:}

\author{
Stephen E. Alway, Ph.D., Chair \\ Randall W. Bryner, Ed.D. \\ Emidio Pistilli, Ph.D. \\ Junaith S. Mohamed, Ph.D.
}

Division of Exercise Physiology

Morgantown, WV

2014

Key Words: Pax7, GCN5, Sirtuin 1, Muscle Repair, Satellite Cells 


\title{
ABSTRACT \\ Post-Translational Modifications of Satellite Cells During the Repair of Injured Skeletal Muscle
}

\author{
Justin E. Sperringer, B.S.
}

\begin{abstract}
Satellite cells are normally a quiescent skeletal muscle stem cell pool that upon activation rapidly proliferate and differentiate to repair damaged muscle fibers. The paired box transcription factor 7 (Pax7) is the canonical biomarker for quiescent, activated, and proliferating satellite cells and is rapidly down-regulated upon differentiation into myofibers. However, the factors that regulate the modulation of Pax 7 are largely unknown. Post-translational modifications to Pax 7 provide a viable means to activate or deactivate this transcription factor through the signaling cascade of skeletal muscle repair and regeneration. The sirtuin 1 (Sirt1) protein, a histone deacetylase, has been shown to be involved in many cellular processes, including the differentiation of myoblasts. Although Sirt1 is noted for its role in the differentiation of myoblasts, it is not known if it directly interacts with Pax7. The general control of amino acid synthesis protein 5-like 2 (GCN5), an acetyltransferase, is known to work in conjunction with Sirt1 modulating PGC-1 $\alpha$ in hepatic gluconeogenesis. With this information, it is logical to test if GCN5 also works with Sirt1 in the satellite cell response to muscle injury. The primary objective of this study is to determine the role of GCN5 and Sirt1 on Pax7-mediated regulation of satellite cell function. We tested the novel hypothesis that GCN5 is a binding partner with Pax7 and acts on Pax7 via acetylation leading to satellite cell activation and proliferation while Sirt1 is another binding partner of Pax7 and acts on Pax7 via deacetylation. The tibialis anterior (TA) muscles of wildtype mice were injected with cardiotoxin (CTX) to induce muscle injury. The TA muscles where harvested 4, 7, 14, or 21 days post-injection to analyze the satellite cell response to regulate muscle repair following the CTX injury. Western Blot data showed that the total protein abundance of Pax7, GCN5, and acetylated protein at 57kD (Pax7 molecular weight) were significantly up-regulated 4, 7, and 14 days post CTX injection, but had returned to basal levels by 21 days post CTX injection. From 4 through 14 days post injection Pax 7 abundance was $~ 592 \%, 204 \%$, and $219 \%$ greater compared to control muscles. GCN5 abundance was $\sim 215 \%, 330 \%$, and $213 \%$ greater from 4 through 14 days post injection, and acetylated protein at $57 \mathrm{kD}$ was $\sim 651 \%, 291 \%$, and $404 \%$ greater compared to controls. The abundance of Sirt1 protein was significantly increased at 14 days post CTX injection with 259\% greater abundance compared to control muscles and approached basal levels by 21 days post CTX injection. Although not significant, there was $\sim 111 \%$ greater abundance of Sirt1 protein 7 days post CTX injection relative to control muscles. Immunoprecipitation studies showed that GCN5 was directly associated with Pax 7 during all recovery time points, with 21 days post CTX injury not having as strong association compared to the other time points. The membrane was then stripped and probed for acetylated lysine, which mirrored the GCN5 association pattern. Sirt1 was also tested for interaction and showed to be directly interacting with Pax7 during the 7, 14, and 21 days post CTX injury time points. Immunohistochemistry confirmed that Pax7 and GCN5 were co-localized to muscle nuclei in the 4 day regenerating muscles; this confirms that Pax7 and GCN5 interact during activation and proliferation of satellite cells. Immunohistochemistry also confirmed that Pax 7 and Sirt1 were colocalized in the 14 day regenerating muscles; this confirms that Pax 7 and Sirt1 interact during the differentiation of myoblasts. These novel data support the hypotheses that GCN5 acetylates Pax7 to rapidly activate and proliferate satellite cells in response to skeletal muscle damage while Sirt1 deacetylates $\operatorname{Pax} 7$ to differentiate myoblasts.
\end{abstract}




\section{Table of Contents}

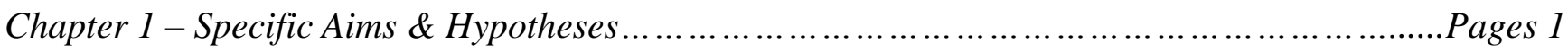

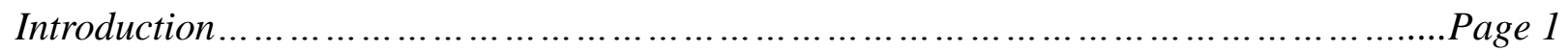

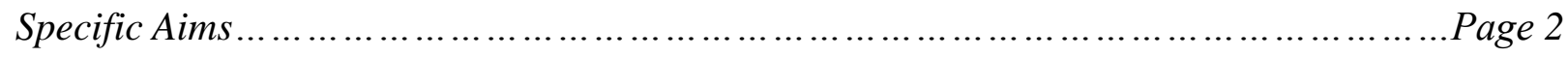

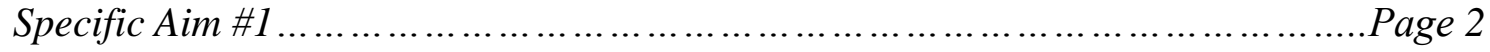

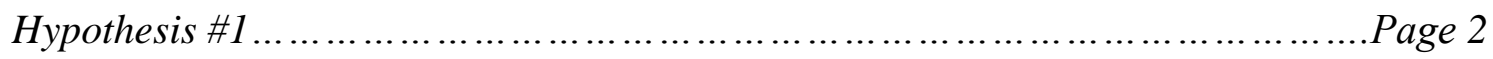

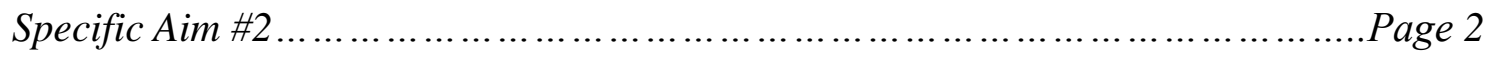

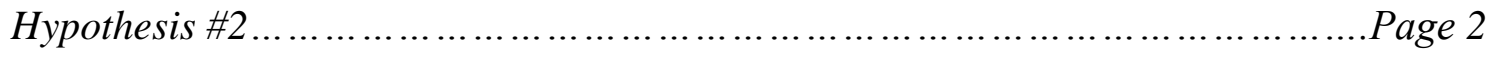

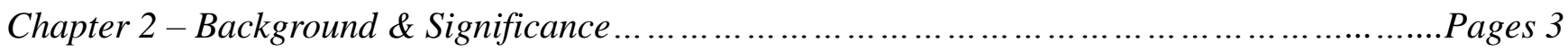

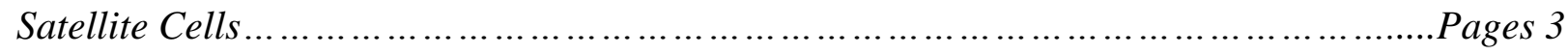

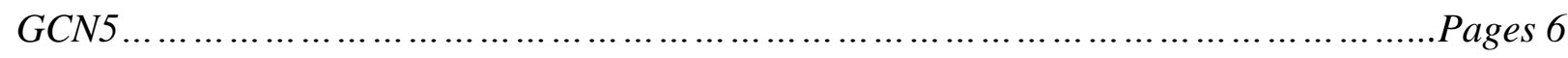

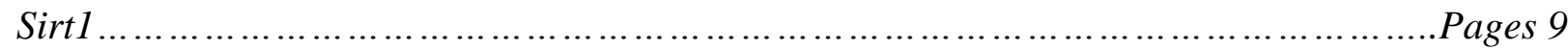

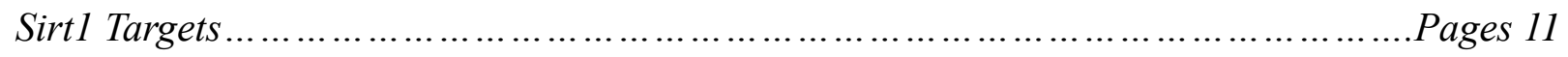

Chapter 3 - Methods \& Procedures Summary .......................................................Pages 13

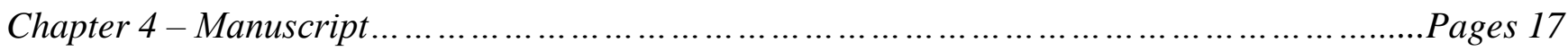

Chapter 5 - Findings, Limitations, \& Future Research................................................Pages 44

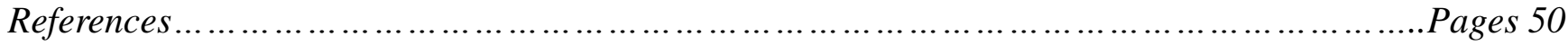

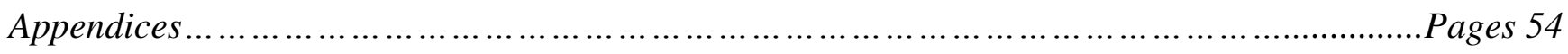




\section{Chapter 1 -Specific Aims \& Hypotheses}

Skeletal muscle damage is a common problem for people of all ages, fitness levels, and the ability of muscle regeneration in response to injury is suppressed in aging and in a variety of metabolic and muscle wasting diseases. Skeletal muscle regeneration is a highly orchestrated process that requires the activation and differentiation of skeletal muscle stem cells, known as satellite cells. While normally quiescent, the self-renewing proliferation of these cells not only maintains the satellite cell population, but also provides numerous myogenic-committed cells that proliferate, differentiate, fuse, and lead to new myofiber formation and repair the contractile properties of the myofibers ${ }^{1-4}$.

The exact process mediating the activation and proliferation of satellite cells is currently not known due to the complex nature of the signaling cascade. However, it is possible that the regulation of satellite cells involves paired box transcription factor 7 (Pax7), because Pax7 is highly expressed in both quiescent and activated satellite cells. Nevertheless, the mechanisms controlling Pax7 function in satellite cells is largely unknown. Our preliminary studies have identified two proteins that may be important for regulating satellite cell function in response to injury repair. Specifically, our preliminary data indicated that the general control of amino acid synthesis protein 5-like 2 (GCN5), physically bound with and activated Pax7 by an acetylation-dependent mechanism in activated satellite cells. However, it was not known if the class III histone deacetylase Sirtuin 1 (Sirt1) physically bound with and deactivated Pax7 during myogenesis in response to muscle repair.

The primary objective of this novel study was to determine the role of GCN5 and Sirt1 on Pax7-mediated regulation of satellite cell function during muscle repair. It was hypothesized that GCN5 is a binding partner of Pax7 and acts on Pax7 via acetylation, leading to satellite cell activation, proliferation, and self-renewal. We also evaluated a second hypothesis that Sirt1 is a binding partner of 
Pax7 and acts on Pax7 via deacetylation, leading to myoblast differentiation. Our rationale for this project is that a delineation of the potential importance of GCN5 and Sirt1 on satellite cell function would potentially provide opportunities for improving muscle repair following injury with persons with metabolic disease and aging, who tend to have reduced rates of injury repair.

The central hypothesis will be addressed by the following two aims:

\section{Specific Aim \#1:}

\section{Determine if GCN5 is a binding partner of Pax7 and acts on Pax7 via acetylation.}

The hypothesis for Specific Aim \#1 is that GCN5 is a binding partner of Pax7, and will transfer acetyl groups to $\operatorname{Pax} 7$.

\section{Specific Aim \#2:}

Determine if Sirt1 is a binding partner of Pax7 and acts on Pax7 via deacetylation.

The hypothesis for Specific Aim \#2 is that Sirt1 is a binding partner of Pax7, and will remove acetyl groups on Pax7 via deacetylation. 


\section{Chapter 2 - Background \& Significance}

\section{Satellite Cells}

Satellite cells are a normally quiescent stem cell population within skeletal muscle. They have acquired their name from their anatomical location, which is between the basal lamina and the sarcolemma of myofibers ${ }^{1}$. Quiescent satellite cells are mitotically inactive and remain in $\mathrm{G}_{0}$ phase until activation $^{1,2}$. The functional aspect of quiescence relates to their anatomical morphology, with these cells having a large nuclear to cytoplasmic ratio, few organelles, a small nucleus, and condensed interphase chromatin ${ }^{4}$. During myogenesis, satellite cells have the ability to undergo symmetric or asymmetric division, with asymmetric division allowing the cell to maintain the satellite cell pool by contributing a new quiescent cell to the pool ${ }^{1-3}$. While the exact signaling for activated satellite cells is unknown, the nucleus expresses certain proteins that indicate what stage they are undergoing.

Using $3 \mathrm{H}$ thymidine tracing experiments, Snow et. al. ${ }^{6}$ showed that satellite cells are mitotically quiescent in adult skeletal muscle, but quickly enter the cell cycle following muscular injury ${ }^{6}$. Commitment to the cell cycle demonstrates that satellite cells will produce proliferating myoblasts that are essential to muscular regeneration ${ }^{1}$. Satellite cells are capable of both symmetric and asymmetric cellular division $^{1,2}$. Symmetric cell division is where the satellite cell divides into two identical daughter cells with the same cellular fate while asymmetric cell division produces one quiescent daughter cell and a progenitor cell (myoblast) ${ }^{3}$. Understanding the nuclear expression of certain proteins indicates what stage they are undergoing. 


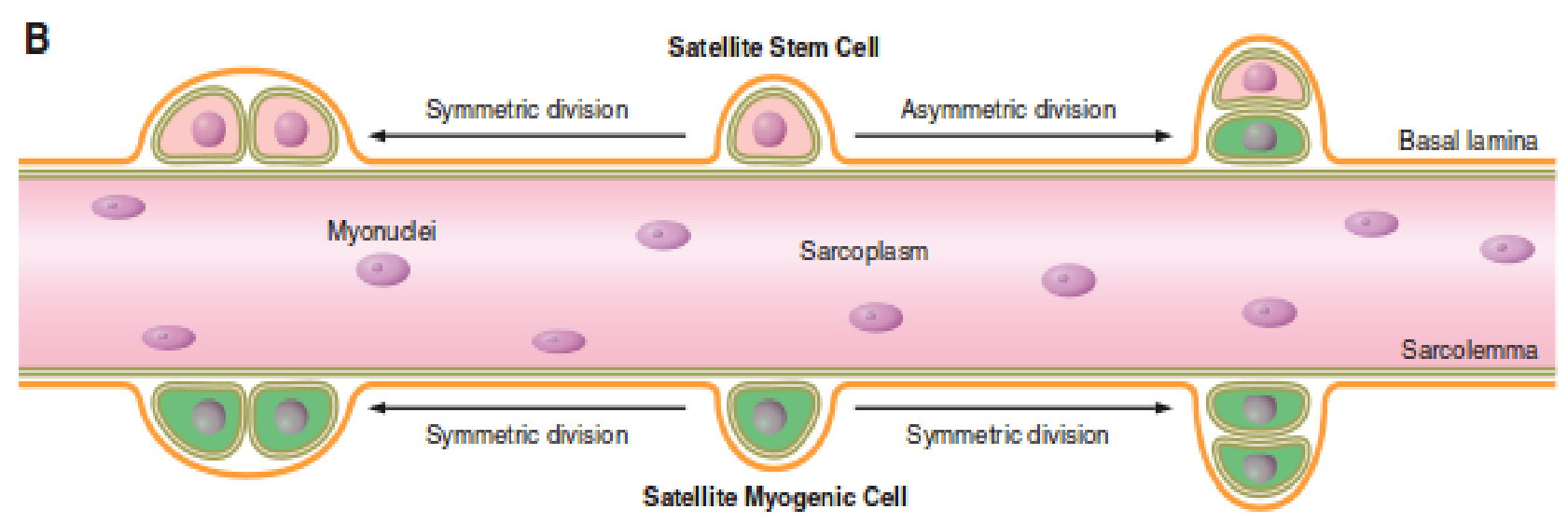

Above image from Yin et. al. ${ }^{1}$

In work published by Schultz et. al., the morphologic structure of satellite cells goes hand in hand with the fact that these cells are mitotically quiescent and transcriptionally inactive in healthy, unstressed muscle ${ }^{1,7}$. Identification of these cells during their progress through quiescence to activation is important for tracking them and understanding their function. Pax7 is the canonical biomarker for quiescent and activated satellite cell, but becomes deactivated upon entering the differentiation stage ${ }^{4}$. Other proteins, such as Myf5 and MyoD, begin to increase their levels during differentiation when the activated satellite cells have committed to differentiate into myoblasts ${ }^{1,4}$. The protein myogenin is another biomarker that is expressed in differentiating myoblasts, leading to complete commitment to a myogenic lineage ${ }^{1}$.

Pax7 is frequently used as the major indicator for satellite cells in the quiescent or proliferative stage. All quiescent, activated, and proliferating satellite cells highly express Pax7, but the level of Pax7 dramatically decreases in differentiating myoblasts and myotubes while other factors, such as MyoD, Myf5, and myogenin become highly expressed ${ }^{4}$. Schultz found that the majority of satellite cells readily enter the cell cycle ( $\sim 80 \%$ - termed the "responsive population") while the remainder does so in a much slower manner (termed the "reserve population") ${ }^{4}$. He proposed that the reserve population undergoes symmetric division, maintaining the satellite cell pool ${ }^{4}$. However, this reserve 
population can and will undergo asymmetric division to enter the proliferative state if extensive muscle growth or regeneration is needed ${ }^{4}$.

After activation, the myogenic-committed satellite cells express both Myf5 and MyoD ${ }^{3}$. The importance of Pax7 is further demonstrated in the satellite cell signaling cascade based on its interactions with Myf5. Pax7 activates Myf5 expression by recruiting histone methyltransferase complex (HMT) and histone H3 lysine $4(\mathrm{H} 3 \mathrm{~K} 4)$ at the promoter of the Myf5 $5^{3,8}$. Pax $7^{+} / \mathrm{Myf}^{+}$cells upregulate the expression of $\mathrm{MyoD}$, triggering the proliferation of the satellite cells ${ }^{8,9}$. Another key component that works in concert with Pax7 is FoxO3, which binds to the promoter region of Pax7 to recruit RNA polymerases ${ }^{10}$. The presence of $\mathrm{MyoD}^{+} / \mathrm{Pax}^{-}$cells indicates differentiating satellite cells that will contribute to new or regenerating myotubes ${ }^{1,3}$.

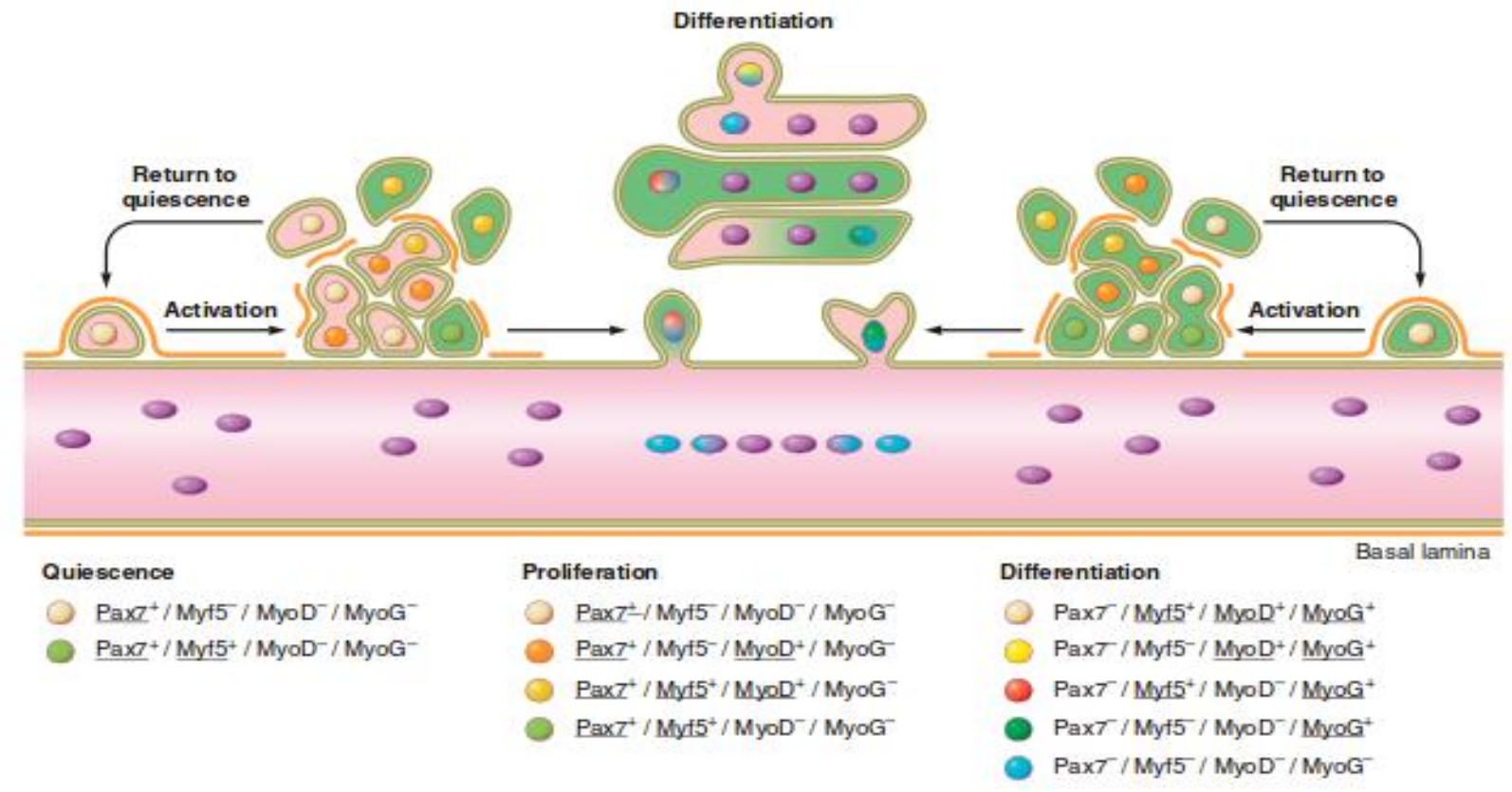

Above picture from Yin et. al. ${ }^{1}$ 
GCN5

Histones are proteins found in eukaryote nuclei that are bound to DNA for packaging, and order the DNA into structures known as nucleosomes. Nucleosomes are the basic units of chromatin composed of DNA wrapped around histone octomers ${ }^{11}$. Nucleosomes consist of approximately 146 base pairs of DNA and two copies each of histones $\mathrm{H} 2 \mathrm{~A}, \mathrm{H} 2 \mathrm{~B}, \mathrm{H} 3$, and $\mathrm{H} 4^{11}$. Histone acetyltransferases (HATs) modify the histones by transferring acetyl groups from acetyl coenzyme A (Acetyl CoA) to the lysine residues ${ }^{11}$. GCN5 is a HAT that primarily targets lysine K14 on H3 as well as lysine $\mathrm{K} 8$ and lysine $\mathrm{K} 16$ on $\mathrm{H} 4{ }^{11,12}$. Because Pax7 is a nuclear transcription factor that is upregulated during the activation and proliferation of satellite cells, post-translational modification of Pax7 may be necessary to activate its transcriptional function. One of the common pathways to activate transcription factors is the modification of their acetylation states (acetylation or deacetylation), which can activate Pax7 to initiate transcriptional function. With this information, GCN5 may be a potential acetyltransferase to activate the satellite cell transcription factor Pax7 by acetylation.

The first metazoan HAT observed was p55. It was also shown to be homologous to yeast GCN $5^{13}$. From there, a whole host of HATs emerged and were subsequently divided into five families: the GCN5-related N-acetyltransferases (GNATs), the MOZ, Ybf2/Sas3, Sas2, and Tip60 (MYST) related HATs, the p300/CREB binding protein/associated factor (CBP/PCAF) HATs, the general transcription factor HATs (TAF1), and the nuclear hormone-related HATs (SRC1 and ACTR/SRC3 $)^{11,14,15}$. Of particular concern for this proposal, vertebrates have two genes encoding for GCN5-like factors, the GNATs and PCAF ${ }^{11,16}$. PCAF stands for $\mathrm{p} 300 / \mathrm{CBP}$ associated factor and is $73 \%$ identical to GCN5 ${ }^{16}$.

There are two domains within the GCN5 structure, the C-terminal domain and the N-terminal domain. The N-terminal domain is very similar to the PCAF and actually contains a sub-domain named the PCAF homology domain. The C-terminal domain contains two sub-domains: the AT domain and 
the bromodomain. It is the AT domain that is responsible for transferring the Acetyl CoA to proteins ${ }^{17-}$ ${ }^{19}$. The bromodomain in GCN5 and PCAF also function as an acetylase ${ }^{11}$. With the work done by Zeng and Zhou in 2002, it was demonstrated that the bromodomain recognizes the acetylated lysine on histones to play a role in chromatin remodeling and transcription activation ${ }^{20}$. Owen et al. were able to show that the bromodomain of GCN5 binds to the acetylated lysine K16 on histone $\mathrm{H} 4{ }^{21}$. However, the PCAF bromodomain was shown to bind to the acetylated lysine K8 on histone H4 tail and the acetylated lysine $\mathrm{K} 14$ on histone $\mathrm{H} 3^{22}$. In both the GCN5 and PCAF bromodomains, the authors provide evidence to show that the bromodomains contribute to the histone acetylation by bridging the acetylation to specific chromosomal transcription sites $^{11,20,21}$. Histone acetylation is a post-translational modification that influences the activity of the histones ${ }^{23}$. Histones that are hypoacetylated are transcriptionally repressed while the hyperacetylated histones are transcriptionally active ${ }^{23}$.

While both of these acetyltransferases play an important role, GCN5 is an essential protein for development in animals ${ }^{11}$. In work done by $\mathrm{Xu}$ et al., GCN5-/- mice expire during embryogenesis because they fail to form the dorsal mesoderm ${ }^{24}$. These animals expired approximately 10.5 days post coitum $^{24}$. The combination GCN5-/- and PCAF -/- mice show a sooner expiration time with deaths occurring between 7.5 and 9.5 days post coitum ${ }^{24}$. However, in PCAF -/- mice, GCN5 is drastically increased as a compensatory mechanism and produce viable offspring ${ }^{24,25}$. This indicates that GCN5 is necessary for proper development through its HAT activity and will compensate for PCAF HAT abnormalities.

An important but unanswered question is how GCN5 is activated to acetylate histones. In work published by Dominy, Jr. et. al., the deacetylase Sirt6 was shown to activate GCN5 ${ }^{5}$. The work looked at how the acetylation and deacetylation of PGC-1 $\alpha$ affected hepatic gluconeogenesis. Activation of PGC-1 $\alpha$ stimulates hepatic gluconeogenesis by increasing the expression of enzymes necessary for the generation of new glucose ${ }^{5}$. Acetylation of PGC- $1 \alpha$ has been shown to repress its activity by relocating 
PGC-1 $\alpha$ away from promotor regions of the target genes. GCN5 is known to acetylate PGC-1 $\alpha$, resulting in its repression not only in the liver, but also in skeletal muscles ${ }^{5,26-28}$.
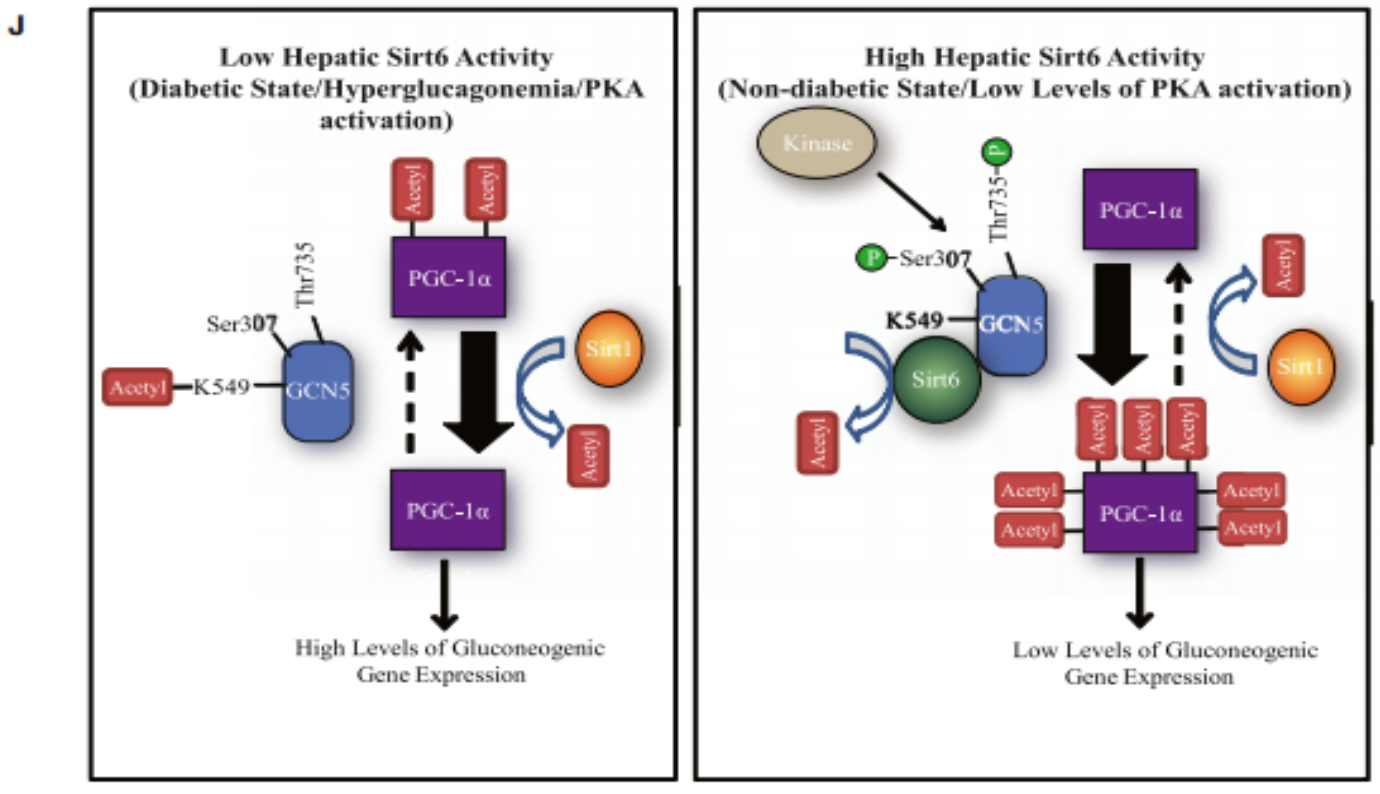

Figure 7. Sirt6 Suppresses the Gluconeogenic Program and Reduces Blood Glucose Levels in Diabetic $d b / d b$ Mice (A-D) Data are pooled from two independent experiments; $n=15$ for GFP-injected $+/ d b$ mice, $n=10$ for Sirt6-injected $+/ d b$ mice, $n=13$ for GFP-injected $d b / d b$ mice, $n=12$ for Sirt6-injected $d b / d b$ mice. Hepatic PEPCK (A), G-6-Pase (B), and PGC-1 $\alpha$ (C) mRNA levels from $+/ d b$ and $d b / d b$ mice injected with GFP or 3xFLAG WT Sirt6-expressing adenovirus. For 3-4 days after tail vein injection of virus, mice were fed ad libitum and then fasted for $16 \mathrm{hr}$ before being sacrificed. (D) Blood glucose levels measured from mice treated as in (A).

(E-G) Hyperinsulinemic-euglycemic clamp data from ab/ob mice injected with GFP or 3xFLAG WT Sirt6 virus. Clamped glucose infusion rate (E). glucose uptake (F), and HGP (G) are shown. (F) Hepatic levels of endogenous Sirt6 mRNA in GFP-infected control mice treated as in (A). Hepatic levels of endogenous Sirt6 mRNA $(\mathrm{H})$ and protein $(\mathrm{l})$ in GFP-infected control mice treated as in (A). Data are from six-GFP injected and seven-Sirt6 injected mice and analyzed by a two-tailed unpaired t test.

(legend continued on next page)

With this information pertaining to GCN5's ability to acetylate histones in the nucleus, it is very possible that GCN5 acts as the initial activator for the activation of Pax7 in the nucleus. Because quiescent and proliferating satellite cells express Pax7, the post-translational modifications to Pax7 are key in understanding the activation process of the satellite cells. However, the activation and differentiation of these myogenic stem cells is necessary for the muscle to regenerate. As stated previously, the differentiation of myoblasts accompanies a complete dissolution of Pax7 expression and a marked increase in Myf5, MyoD, and MyoG expression levels. The preliminary data suggests that GCN5 is the activator of Pax7 by acetylation, it is logical that a deacetylase is responsible for the deactivation of Pax7 allowing differentiation to continue. 
Sirtuins are silent information regulators of the nicotinamide adenine dinucleotide-dependent deacetylases in the histone family ${ }^{29,30}$. There are currently seven members of this family, all of which consist of a central catalytic domain, but differ at the $\mathrm{C}$ and $\mathrm{N}$-terminal domains ${ }^{29}$. One major difference between the sirtuins and other classes of histone deacetylases is that all sirtuins require $\mathrm{NAD}^{+}$for their enzymatic activity ${ }^{29,31,32}$. Sirt1 is a focus of this study and is found primarily (although not exclusively) in the nucleus ${ }^{29}$. Sirt1 is known to act as a catalyst in the transfer of acetyl groups from the target protein to the $\mathrm{NAD}^{+}$, leading to the formation of NAM and deacetylate the target ${ }^{27,29,31-35}$.

Due to the requirement of $\mathrm{NAD}^{+}$, Sirt1 is considered an energy sensor that is increased in response to increased $\mathrm{NAD}^{+}$availability ${ }^{29}$. This is attributed to the $\mathrm{NAD}^{+} / \mathrm{NADH}$ ratio, which drives the mitochondrial production of ATP through the NADH dehydrogenase complex ${ }^{29}$. The NAD $\mathrm{NAADH}^{+}$ ratio has also been found to be increased when nutrients are limited and when energy expenditure is increased, which are also conditions where Sirt1 activation has been observed ${ }^{29,30,32}$. Another level of $\mathrm{NAD}^{+}$regulation that relates directly to Sirt1 activity is the $\mathrm{NAD}^{+}$salvage pathway, where NAM is converted to NMN (NAM mononucleotide) by the NAM phosphoribosyltransferase (Nampt) and converted back to $\mathrm{NAD}^{+}$by NMN adenylyltransferase ${ }^{29-32}$. The key to this pathway is Nampt, which has been found to be the rate-limiting step and increases Sirt1 activity ${ }^{29,31,33}$.

With this information, it can be shown that any condition increasing the $\mathrm{NAD}^{+} / \mathrm{NADH}$ ratio by increasing the production of $\mathrm{NAD}^{+}$will lead to elevated Sirt1 activity ${ }^{31}$. The converse of this is also true where decreasing the $\mathrm{NAD}^{+} / \mathrm{NADH}$ ratio or competitive consumers of $\mathrm{NAD}^{+}$can lead to inhibition of Sirt 1 activity ${ }^{31}$. One of these competitive $\mathrm{NAD}^{+}$consumers that indirectly inhibits Sirt1 activity is the poly-ADP ribose polymerase 1 (PARP-1) $)^{28,29,31}$. In studies conducted by Bai et al., it was demonstrated that there is an increase in Sirt1 deacetylase activity through inhibition of PARP- $1^{36,37}$. 
The proposed primary roles of Sirt1 are to promote mitochondrial biogenesis and increase gene transcription in skeletal muscle ${ }^{29}$. Sirt1 has been shown to target a number of different histones and other proteins, with three major targets: the peroxisome proliferator-activated receptor $\gamma$-coactivator 1$\alpha$ (PGC1- $\alpha)$, myogenic determination factor (MyoD), and the forkhead box transcription factors $\mathrm{O} 1$ and $3 \mathrm{a}(\text { FoxO1 \& Fox3a) })^{27-30,34,36-39}$. 


\section{Sirt1 Targets}

PGC1- $\alpha$ plays key roles in mitochondrial biogenesis and fatty acid oxidation in the skeletal muscle. Activated Sirt1, via sensing decreased nutrient availability and/or an increased NAD ${ }^{+} / \mathrm{NADH}$ ratio, deacetylates PGC1- $\alpha$ at the promoter region of genes involved in mitochondrial biogenesis and fatty acid oxidation, resulting in increased transcription of PGC1- $\alpha$-dependent genes ${ }^{28,31,37}$. Another suggested possible target for Sirt1 deacetylation is the metabolic sensor AMP activated protein kinase (AMPK), which also increases mitochondrial biogenesis and fatty acid oxidation ${ }^{31}$. It has also been shown that AMPK can regulate Sirt1 activity indirectly by increasing the NAD ${ }^{+} / \mathrm{NADH}_{\text {ratio }}{ }^{31}$. This would suggest a positive feedback system between Sirt1 and AMPK ${ }^{31}$.

Sirt 1 also has been demonstrated to complex with the histone acetyltransferases p300/CBP associated factor. These transferases impose control over amino acid synthesis in muscle and are known to be the master regulator of the satellite cell differentiation factor MyoD ${ }^{29,38}$. During periods of increased $\mathrm{NAD}^{+}$, Sirt1 maintains MyoD in the deacetylated state, therefore inhibiting MyoD's $\operatorname{transcription}^{38}$. This illustrates the negative regulation of Sirt1 on MyoD, resulting in inhibition of the differentiation process of myoblasts ${ }^{38}$.

In a follow-up study by Fulco et al., it was noted that myoblast differentiation (via MyoD) was impaired during glucose restriction and was dependent on the AMPK-Nampt-Sirt1 pathway ${ }^{33}$. The authors concluded that this pathway acts as a checkpoint for differentiation of satellite cells to prevent the energy demanding differentiation process due to low nutrient availability ${ }^{33}$. However, Canto et al. have proposed that the interaction of Sirt1 and AMPK is much more complex than previously thought. They demonstrated that the inhibition of Nampt did not inhibit the NAD ${ }^{+} / \mathrm{NADH}$ ratio or PGC1- $\alpha$ acetylation $^{31}$.

Over-expression of Sirt1 has been shown to promote proliferation of satellite cells ${ }^{29,38}$. Rathbone et al. suggest that the enhanced proliferative capacity of satellite cells in Sirt1 over- 
expression is likely due to the inhibition of cyclin D/CDK4 inhibitor p $21^{38}$. Specifically, Sirt1 decreases $\mathrm{p} 21^{\text {Waf/Cip1 }}$ protein which inhibits cyclin D-cdk4/6 activity, which progresses the cell cycle ${ }^{38}$. This data implies that Sirt1 regulates the cell cycle progression in early G1 through S phases ${ }^{38}$.

The family of Sirt proteins are known deacetylases, with Sirt1 being the primary antagonist of GCN5 in the PGC-1 $\alpha$ pathway, since both act upon PGC-1 $\alpha$. With this information, Dominy, Jr. et. al. tested several Sirts and found that Sirt6 actually dramatically increased the acetylation of PGC-1 $\alpha$, the complete opposite of what was thought would happen ${ }^{5}$. Co-immunopricipitations of FLAG Sirt6 from nuclear fractions of U-2 OS found endogenous GCN5 bound to Sirt6 ${ }^{5}$. The converse was also found true with FLAG GCN5 being bound to Sirt6. This showed a clear interaction of the two proteins ${ }^{5}$. 


\title{
Chapter 3 - Methods and Procedures Summary
}

\author{
Study Design Overview
}

Short term and long term studies will be conducted to observe the different stages of satellite cells during activation, proliferation, and differentiation. For the short term group, the mice $(n=12)$ will be injected in the right and left tibialis anterior (TA) with 1x cardiotoxin (CTX) and 1x phosphate buffered saline (PBS), respectively, with the right being the experimental leg and the left being the control leg. The animals will then be sacrificed 4 days post injection to observe activation and proliferation of satellite cells. Muscle tissues will then be subject to a battery of experimental procedures outlined below to determine Pax7, GCN5, and Sirt interactions. The long term group of mice will be separated into 3 groups (each group, $n=4$ ) to observe satellite cell differentiation and muscle regeneration. The mice will be subject to the same experimental procedures to induce muscle damage, but will be sacrificed at 7, 14, and 21 days post injection to observe varying degrees of muscle repair and regeneration. These muscle tissues with varying degrees of repair and regeneration will then be subject to the same battery of experimental procedures to observe Pax7, GCN5, and Sirt interactions. As described in the specific aims and hypotheses, the short term and long term design will allow for the observation of these proteins during different stages of satellite cell activation, proliferation, and differentiation.

\section{Mouse Model}

C57BL/6, Sirt ${ }^{\text {wtflox }}$ mice between 3 to 6 months of age were obtained from Jackson Labs. All mice were conditional wild-types. Mice were anesthetized with 2-4\% isoflurane and allowed to rest 10 minutes prior to experimental procedures. The tibialis anterior (TA) muscle of one limb was injected 
with $70 \mu \mathrm{L}\left(1 \mathrm{mg} \cdot \mathrm{mL}^{-1}\right.$ in distilled $\left.\mathrm{H}_{2} \mathrm{O}\right)$ of cardiotoxin (CTX) from naja mossambic mossambic obtained from Sigma-Aldrich. Seventy microliters of 1x phosphate buffered saline (PBS) was injected along the length of the contralateral TA muscle. The animals were examined 4, 7, 14, or 21 days after CTX or PBS injection. The animals were housed at $20^{\circ} \mathrm{C}$ in barrier-controlled conditions under a 12:12 hour light-dark cycle. Proper animal care standards were followed by adhering to the recommendations for the care of laboratory animals as advocated by the American Association for Accreditation of Laboratory Animal Care and by following the policies and procedures detailed in the Guide for the Care and Use of Laboratory Animals as published by the United States Department of Health and Human Services and proclaimed in the Animal Welfare Act (PL89-544, PL91-979, and PL94-279). All experimental procedures carried approval by the Institutional Animal Care and Use Committee from West Virginia University.

\section{Surgical Procedures}

The mice were anesthetized with $2-4 \%$ isoflurane and this was maintained throughout the terminal surgeries. Once the TA muscles were harvested, the mice were euthanized by myocardial excision.

Western Blot Analysis

Whole muscle samples were extracted using RIPA lysis buffer to enable protein extraction from the cytoplasm, membrane, and nuclear proteins. Coomassie (Bradford) protein assay was conducted to acquire the protein concentrations for loading samples prior to gel electrophoresis. Protein lysate of $12.5 \mu \mathrm{g}$ was separated by protein electrophoresis using 4-12\% Bis-Tris (NuPage, Invitrogen CA) gels at 200 volts. The proteins were transferred to a nitrocellulose membrane (Protran BA 85, Whatman GE 
Healthcare Life Sciences) at $4^{\circ} \mathrm{C}$ for $2: 20$ hours at $170 \mathrm{~mA}$ in transfer buffer. The membranes were then cut for specific proteins and blocked in 2\% Advanced Enhanced Chemiluminescence (ECL) blocking reagent (GE Healthcare UK Limited) for 1 hour prior to incubating overnight with gentle rocking at $4^{\circ} \mathrm{C}$ in the appropriate antibodies. The following day, the membranes were washed in Tris buffered saline with $0.1 \%$ Tween-20 (TBST) then incubated in the appropriate horse radish peroxidase conjugated secondary antibody for 1 hour. The membranes were washed in TBST, incubated in ECL according to the manufacturer's instructions, and imaged using G:BOX (Syngene).

\section{Immunoprecipitation}

To reduce non-specific binding, $175 \mu \mathrm{g} \cdot \mu \mathrm{L}^{-1}$ of protein was pre-cleaned with $25 \mu \mathrm{L}$ of protein $\mathrm{A} / \mathrm{G}$ beads (Invitrogen) for 1 hour with rotation at $4^{\circ} \mathrm{C}$. Beads were separated from protein using a magnetic separator (Dynal Bead Separator, Invitrogen). The Pax7 antibody (Santa Cruz) and lysate were co-incubated for 2 hours at $4^{\circ} \mathrm{C}$. The antigen and antibody solution was added to new pre-cleaned $\mathrm{A} / \mathrm{G}$ beads and incubated overnight at $4^{\circ} \mathrm{C}$. Beads were then separated using a magnetic separator and washed three times in a washing buffer before electrophoresis. Protein in the resulting lysate was

separated by routine Western Blot methods that have been established in our laboratory ${ }^{40,41,43}$.

\section{Immunohistochemistry}

Frozen muscle sections $(7 \mu \mathrm{m})$ were obtained with a Leica CM3050 S cryostat and placed on FisherBrand Superfrost Plus glass slides. The tissue sections fixed in $4 \%$ paraformaldehyde and permeabilized in $0.4 \%$ Triton $\mathrm{X}$ at $4^{\circ} \mathrm{C}$. The slides were then blocked hour in normal goat serum and incubated with a Pax7-FITC tagged antibody (Developmental Studies Hybridoma Bank) at 1:50 dilution overnight at $4^{\circ} \mathrm{C}$. The following morning, the slides were washed in PBS then incubated in 
diluted horse serum for blocking followed by overnight incubation at $4{ }^{\circ} \mathrm{C}$ in either GCN5 or Sirt1. After incubating the slides in appropriate secondary antibody, the slides were then washed and covered with 4, 6-diamidino-2-phenylindole (DAPI) to visualized the nuclei in the tissue section (ProLong Gold Antifade Reagent with DAPI, Invitrogen). An Olympus MVX10 MacroView microscope equipped with an Hamamatsu ORCA_Flash 4.0v2 sCMOS camera was used for fluorescent imaging using EXFO X-Cite 120 fluorescence illumination system. Max zoom of 25.2x magnification was used to acquire images. The software used was CellSens 1.9 Dimension Acquisition Software.

\section{Statistical Analysis}

All blot quantifications were obtained using GelQuant.NET version 1.8.2

(BiochemLabSolutions.com). Quantified values were then normalized to appropriate controls and analyzed using GraphPad Prism 6 (GraphPad Software, Inc.). Statistical significance values were obtained by a 2-way ANOVA. 
Chapter 4 - Manuscript

\title{
Post-Translational Modifications of Satellite Cells During the Repair and Regeneration of Injured Skeletal Muscle
}

\author{
Justin E. Sperringer ${ }^{1,3}$, Junaith S. Mohamed ${ }^{1,3}$, \& Stephen E. Alway ${ }^{1,2,3}$
}

${ }^{1}$ Laboratory of Muscle Biology and Sarcopenia, Department of Exercise Physiology, West Virginia University School of Medicine, ${ }^{2}$ West Virginia Center for Clinical and Translational Science Institute, and ${ }^{3}$ Center for Cardiovascular, and Respiratory Sciences, West Virginia University School of Medicine, Morgantown, WV 26506-9227 


\section{Abstract}

Satellite cells are normally a quiescent skeletal muscle stem cell pool that upon activation rapidly proliferate and differentiate to repair damaged muscle fibers. The paired box transcription factor 7 (Pax7) is the canonical biomarker for quiescent, activated, and proliferating satellite cells and is rapidly down-regulated upon differentiation into myofibers. However, the factors that regulate the modulation of Pax7 are largely unknown. Post-translational modifications to Pax7 provide a viable means to activate or deactivate this transcription factor through the signaling cascade of skeletal muscle repair and regeneration. The sirtuin 1 (Sirt1) protein, a histone deacetylase, has been shown to be involved in many cellular processes, including the differentiation of myoblasts. Although Sirt1 is noted for its role in the differentiation of myoblasts, it is not known if it directly interacts with Pax7. The general control of amino acid synthesis protein 5-like 2 (GCN5), an acetyltransferase, is known to work in conjunction with Sirt1 modulating PGC-1 $\alpha$ in hepatic gluconeogenesis. With this information, it is logical to test if GCN5 also works with Sirt1 in the satellite cell response to muscle injury. The primary objective of this study is to determine the role of GCN5 and Sirt1 on Pax7-mediated regulation of satellite cell function. We tested the novel hypothesis that GCN5 is a binding partner of Pax7 and acts on Pax7 via acetylation leading to satellite cell activation and proliferation while Sirt1 is another binding partner of Pax7 and acts on Pax7 via deacetylation. The tibialis anterior (TA) muscles of wildtype mice were injected with cardiotoxin (CTX) to induce muscle injury. The TA muscles where harvested 4, 7, 14, or 21 days post-injection to analyze the satellite cell response to regulate muscle repair following the CTX injury. Western Blot data showed that the total protein abundance of Pax7, GCN5, and acetylated protein at 57kD (Pax7 molecular weight) were significantly up-regulated 4, 7 , and 14 days post CTX injection, but had returned to basal levels by 21 days post CTX injection. From 4 through 14 days post injection Pax7 abundance was 592\%, 204\%, and 219\% greater compared to control muscles. GCN5 abundance was $\sim 215 \%, 330 \%$, and $213 \%$ greater from 4 through 14 days post 
injection, and acetylated protein at $57 \mathrm{kD}$ was $\sim 651 \%, 291 \%$, and $404 \%$ greater compared to controls. The abundance of Sirt1 protein was significantly increased at 14 days post CTX injection with $~ 259 \%$ greater abundance compared to control muscles and approached basal levels by 21 days post CTX injection. Although not significant, there was $\sim 111 \%$ greater abundance of Sirt1 protein 7 days post CTX injection relative to control muscles. Immunoprecipitation studies showed that GCN5 was directly associated with Pax 7 during all recovery time points, with 21 days post CTX injury not having as strong association compared to the other time points. The membrane was then stripped and probed for acetylated lysine, which mirrored the GCN5 association pattern. Sirt1 was also shown to be directly interacting with Pax 7 during the 7, 14, and 21 days post CTX injury time points.

Immunohistochemistry confirmed that Pax7 and GCN5 were co-localized to muscle nuclei in the 4 day regenerating muscles; this confirms that Pax7 and GCN5 interact during activation and proliferation of satellite cells. Immunohistochemistry also confirmed that Pax7 and Sirt1 were co-localized in the 14 day regenerating muscles; this confirms that Pax7 and Sirt1 interact during the differentiation of myoblasts. These novel data support the hypotheses that GCN5 acetylates Pax7 to rapidly activate and proliferate satellite cells in response to skeletal muscle damage while Sirt1 deacetylates Pax7 to differentiate myoblasts.

Key Words: Pax7, GCN5, Sirtuin 1, Muscle Repair, Satellite Cells 


\section{Introduction}

Skeletal muscle damage is a common problem for people of all ages, fitness levels, and the ability of muscle regeneration in response to injury is suppressed in aging and in a variety of metabolic and muscle wasting diseases. Skeletal muscle regeneration is a highly orchestrated process that requires the activation and differentiation of skeletal muscle stem cells, known as satellite cells. While normally quiescent, the self-renewing proliferation of these cells not only maintains the satellite cell population, but also provides numerous myogenic-committed cells that proliferate, differentiate, fuse, and lead to new myofiber formation and repair the contractile properties of the myofibers ${ }^{1-4}$.

The exact process mediating the activation and proliferation of satellite cells is currently not known due to the complex nature of the signaling cascade. However, it is possible that the regulation of satellite cells involves paired box transcription factor 7 (Pax7), because Pax7 is highly expressed in both quiescent and activated satellite cells. Nevertheless, the mechanisms controlling Pax7 function in satellite cells is largely unknown. Our preliminary studies have identified two proteins that may be important for regulating satellite cell function in response to injury repair. Specifically, our preliminary data indicated that the general control of amino acid synthesis protein 5-like 2 (GCN5), physically bound with and activated Pax7 by an acetylation-dependent mechanism in activated satellite cells. However, it was not known if the class III histone deacetylase Sirtuin 1 (Sirt1) physically bound with and deactivated Pax7 during myogenesis in response to muscle repair.

The primary objective of this novel study was to determine the role of GCN5 and Sirt1 on Pax7-mediated regulation of satellite cell function during muscle repair. It was hypothesized that GCN5 is a binding partner of Pax7 and acts on Pax7 via acetylation, leading to satellite cell activation, proliferation, and self-renewal. We also evaluated a second hypothesis that Sirt1 is a binding partner of Pax7 and acts on Pax7 via deacetylation, leading to satellite cell differentiation. Our rationale for this project is that a delineation of the potential importance of GCN5 and Sirt1 on satellite cell function 
would potentially provide opportunities for improving muscle repair following injury with persons with metabolic disease and aging, who tend to have reduced rates of injury repair.

\section{Methods}

\section{Mouse Model}

C57BL/6, Sirt ${ }^{\text {wt/flox }}$ mice between 3 to 6 months of age were obtained from Jackson Labs. All mice were conditional wild-types. Mice were anesthetized with 2-4\% isoflurane and allowed to rest 10 minutes prior to experimental procedures. The tibialis anterior (TA) muscle of one limb was injected with $70 \mu \mathrm{L}\left(1 \mathrm{mg} \cdot \mathrm{mL}^{-1}\right.$ in distilled $\left.\mathrm{H}_{2} \mathrm{O}\right)$ of cardiotoxin (CTX) from naja mossambic mossambic obtained from Sigma-Aldrich. Seventy microliters of 1x phosphate buffered saline (PBS) was injected along the length of the contralateral TA muscle. The animals were examined 4, 7, 14, or 21 days after

CTX or PBS injection. The animals were housed at $20^{\circ} \mathrm{C}$ in barrier-controlled conditions under a 12:12 hour light-dark cycle. Proper animal care standards were followed by adhering to the recommendations for the care of laboratory animals as advocated by the American Association for Accreditation of Laboratory Animal Care and by following the policies and procedures detailed in the Guide for the Care and Use of Laboratory Animals as published by the United States Department of Health and Human Services and proclaimed in the Animal Welfare Act (PL89-544, PL91-979, and PL94-279). All experimental procedures carried approval by the Institutional Animal Care and Use Committee from West Virginia University.

\section{Surgical Procedures}

The mice were anesthetized with $2-4 \%$ isoflurane and this was maintained throughout the terminal surgeries. Once the TA muscles were harvested, the mice were euthanized by myocardial excision. 
Western Blot Analysis

Whole muscle samples were extracted using a RIPA lysis buffer. Coomassie (Bradford) protein assay was conducted to acquire the protein concentrations for loading samples prior to gel

electrophoresis. Protein lysate of $12.5 \mu \mathrm{g}$ was separated by protein electrophoresis using 4-12\% Bis-Tris (NuPage, Invitrogen CA) gels at 200 volts. The proteins were transferred to a nitrocellulose membrane (Protran BA 85, Whatman GE Healthcare Life Sciences) at $4^{\circ} \mathrm{C}$ for 2:20 hours at $170 \mathrm{~mA}$ in transfer buffer. The membranes were then cut for specific proteins and blocked in 2\% Advanced Enhanced Chemiluminescence (ECL) blocking reagent (GE Healthcare UK Limited) for 1 hour prior to incubating overnight with gentle rocking at $4{ }^{\circ} \mathrm{C}$ in the appropriate antibodies. The following day, the membranes were washed in Tris buffered saline with $0.1 \%$ Tween-20 (TBST) then incubated in the appropriate horse radish peroxidase conjugated secondary antibody for 1 hour. The membranes were washed in TBST, incubated in ECL according to the manufacturer's instructions, and imaged using G:BOX (Syngene).

\section{Immunoprecipitation}

To reduce non-specific binding, $175 \mu \mathrm{g} \cdot \mu \mathrm{L}^{-1}$ of protein was pre-cleaned with $25 \mu \mathrm{L}$ of protein $\mathrm{A} / \mathrm{G}$ beads (Invitrogen) for 1 hour with rotation at $4^{\circ} \mathrm{C}$. Beads were separated from protein using a magnetic separator (Dynal Bead Separator, Invitrogen). The Pax7 antibody (Santa Cruz) and lysate were co-incubated for 2 hours at $4^{\circ} \mathrm{C}$. The antigen and antibody solution was added to new pre-cleaned $\mathrm{A} / \mathrm{G}$ beads and incubated overnight at $4^{\circ} \mathrm{C}$. Beads were then separated using a magnetic separator and washed three times in washing buffer before electrophoresis. Protein in the resulting lysate were

separated by routine Western Blot methods that have been established in our laboratory ${ }^{40,41,43}$. 


\section{Immunohistochemistry}

Frozen muscle sections $(7 \mu \mathrm{m})$ were obtained with a Leica CM3050 S cryostat and placed on FisherBrand Superfrost Plus glass slides. The tissue sections fixed in $4 \%$ paraformaldehyde and permeabilized in $0.4 \%$ Triton $\mathrm{X}$ at $4^{\circ} \mathrm{C}$. The slides were then blocked hour in normal goat serum and incubated with a Pax7-FITC tagged antibody (Developmental Studies Hybridoma Bank) at 1:50 dilution overnight at $4^{\circ} \mathrm{C}$. The following morning, the slides were washed in PBS then incubated in diluted horse serum followed by overnight incubation at $4^{\circ} \mathrm{C}$ in either GCN5 or Sirt1. After incubating the slides in appropriate secondary antibody, the slides were then washed and covered with 4, 6diamidino-2-phenylindole (DAPI) to visualized the nuclei in the tissue section (ProLong Gold Antifade Reagent with DAPI, Invitrogen). An Olympus MVX10 MacroView microscope equipped with an Hamamatsu ORCA_Flash 4.0v2 sCMOS camera was used for fluorescent imaging using EXFO X-Cite 120 fluorescence illumination system. Max zoom of 25.2x magnification was used to acquire images. The software used was CellSens 1.9 Dimension Acquisition Software.

\section{Statistical Analysis}

All blot quantifications were obtained using GelQuant.NET version 1.8.2

(BiochemLabSolutions.com). Quantified values were then normalized to appropriate controls and analyzed using GraphPad Prism 6 (GraphPad Software, Inc.). Statistical significance values were obtained by a 2-way ANOVA. 


\section{Results}

Determine if GCN5 is necessary for Pax7 acetylation

It was hypothesized that GCN5 is a binding partner of Pax7 and acts on Pax7 via acetylation, leading to satellite cells activation and proliferation. Before the direct interaction of Pax7 and GCN5 could be assessed, the presence of GCN5 in CTX injured muscles needed to be confirmed. Western Blot analysis was performed for all recovery periods to determine expression of the proteins of interest (Appendix Figures 1-5).

Pax7 is the canonical biomarker for satellite cells and its expression is dramatically upregulated upon muscle injury ${ }^{1-4}$. Using Western Blot analysis to determine protein content from 4-21 days post injection, we were able to illustrate Pax7 expression through the various stages of muscle regeneration (Figure 1). Four days post injection of CTX into the TA indicates the early injury phase and should correspond to significant activation of satellite cells, resulting in dramatic up-regulation of Pax $7^{+}$cells. As demonstrated in Figure 1, 4 days of recovery after CTX injury resulted in significant up-regulation of $\operatorname{Pax} 7(\mathrm{p}=0.003)$. This corresponded to a 592.2\% greater Pax7 protein content in experimental CTX injected muscles compared to control PBS injected muscles. By 7 days post CTX injection, some of the myoblasts should have begun differentiating to regenerate the damaged muscle but the majority of myoblasts will continue to proliferate and provide sufficient nuclei for the regeneration process. The data show that $\operatorname{Pax} 7$ abundance is significantly up-regulated by $204.1 \%$ as compared to the control muscle $(\mathrm{p}=0.006) 7$ days post CTX injury (Figure 1). By 14 days post CTX injection, it would be expected to see a leveling off of Pax 7 protein expression, as the differentiation of myoblasts should be more prominent for the repair process. However, Pax 7 protein abundance remained elevated by $219.1 \%$ as compared to the control muscle $(\mathrm{p}<0.001)$ after 14 days of recovery. CTX injected muscle has regained the muscle weight and even gained mass (hypertrophied) and Pax 7 protein abundance had returned to basal levels after 21 days of recovery (Appendix Table 1). 


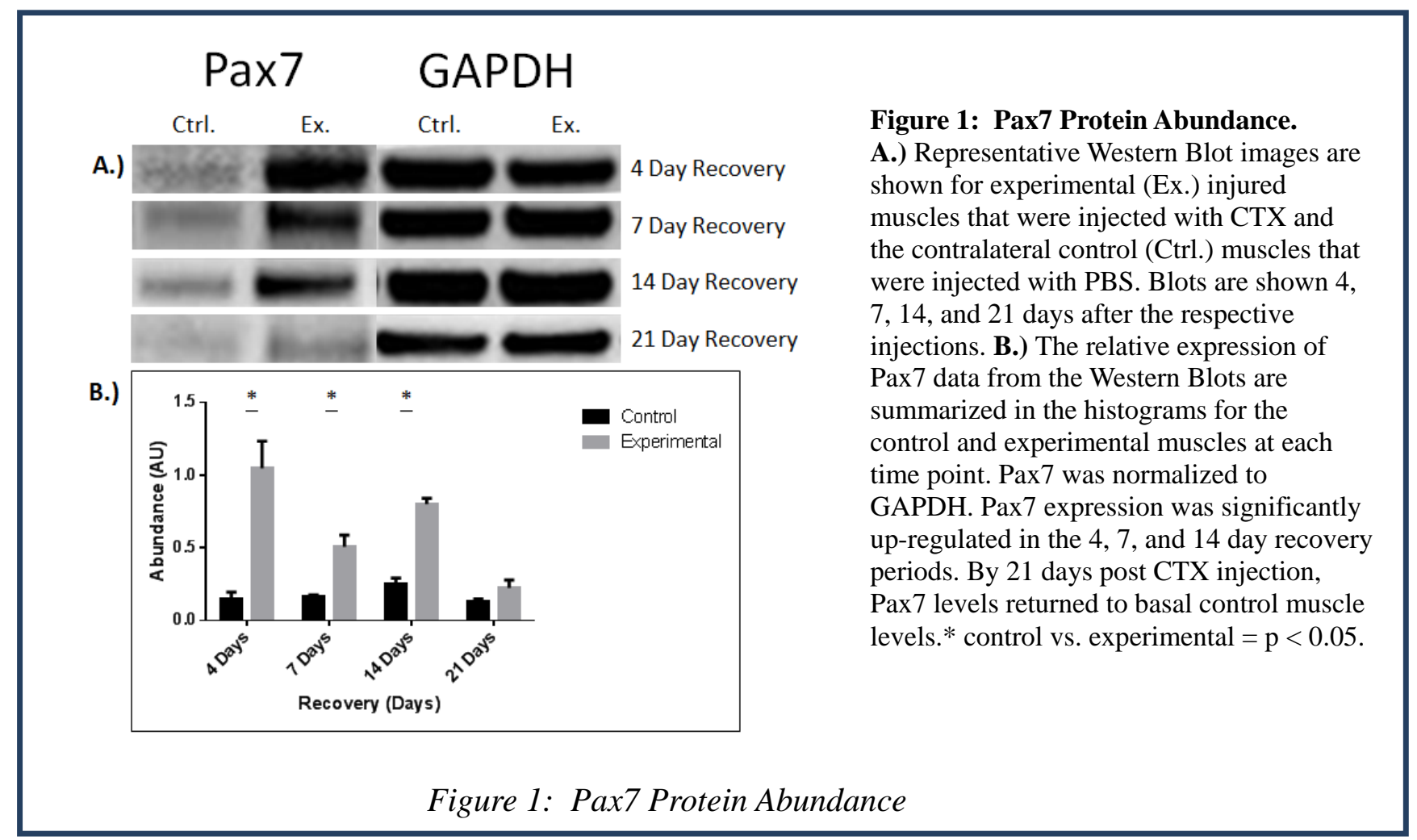

While it is known that Pax7 is expressed in quiescent, activated, and proliferating satellite cells, the modifications to Pax7 itself are largely unknown in the satellite cell signaling cascade. Our preliminary data suggested that the acetyltransferase GCN5 associated with Pax7 during the satellite cell response to muscle injury. To follow-up these observations GCN5 was studied using Western Blots. We found that 4, 7, and 14 days post CTX injury, GCN5 protein content was significantly up-regulated in the experimental muscle compared to the control muscles (Figure 2). GCN5 protein content was found to be significantly greater $(\mathrm{p}<0.0001)$ in 4,7 , and 14 day recovery muscles (Figure 2 ). This resulted in $215.5 \%, 330.4 \%$, and $212.9 \%$ greater amount of protein compared to control muscles, respectively. These data would be consistent with the idea that GNC5 is an important regulator of satellite cell proliferation (e.g., at day 4), but is trending to return to basal levels during maturation and differentiation of the myoblasts (e.g., days 14 and 21). 


\section{GCN5 GAPDH}

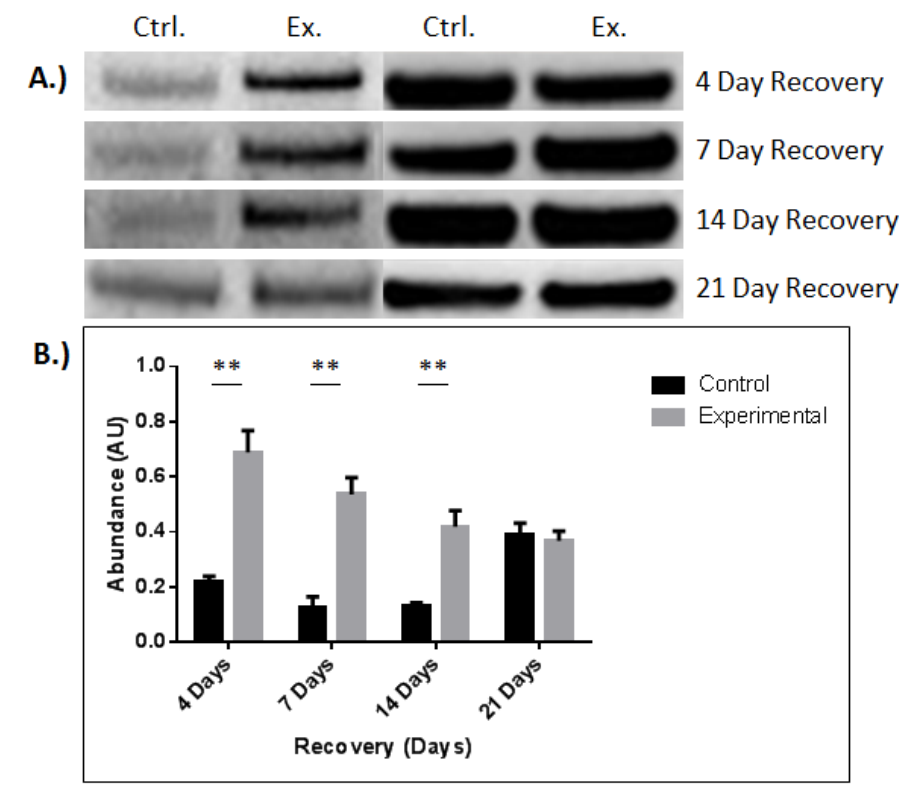

Figure 2: GCN5 Protein Abundance. A.) Representative Western Blot images are shown for experimental (Ex.) injured muscles that were injected with CTX, and the contralateral control (Ctrl.) muscles that were injected with PBS. Blots are shown for $4,7,14$, and 21 days after the respective injections. B.) The relative expression of GCN5 data from the Western Blots are summarized in the histograms for the control and experimental muscles at each time point. GCN5 was normalized to GAPDH. GCN5 expression was significantly up-regulated in the 4,7 , and 14 day recovery periods. By 21 days post CTX injection, GCN5 levels returned to basal control muscle levels. ** control vs. experimental $=\mathrm{p}<0.01$.

Figure 2: GCN5 Protein Abundance

Since GCN5 is an acetyltransferase that is hypothesized to be acting on Pax7 in the satellite cell mediated repair and regeneration of injured muscle, it was necessary to test for acetylated protein in the Western Blot data. The Pax7 blot was stripped and probed with an acetylated lysine to test for acetylated protein. Although we recognize that the Western Blot is not-specific for Pax7, and the probe for acetylation will only show total acetylated protein in the Pax 7 range of $57 \mathrm{kD}$ we have interpreted the change in acetylated protein at $57 \mathrm{kD}$ to be indicative of Pax7 acetylation. Our data show that acetylation at 57kD (i.e., Pax7) was elevated during the early points of satellite cell proliferation (e.g., days 4-14) but declined during the period when differentiation of myoblasts rather than proliferation would be the dominant signal (Figure 3). Acetylated protein at the $57 \mathrm{kD}$ range was found to be significantly up-regulated ( $\mathrm{p}<0.0001$ ) across the 4,7 , and 14 day recovery time points (Figure 3 ). This resulted in $650.7 \%, 291.2 \%$, and $403.7 \%$ greater amount of protein compared to control muscles, respectively $(\mathrm{p}<0.05)$. 


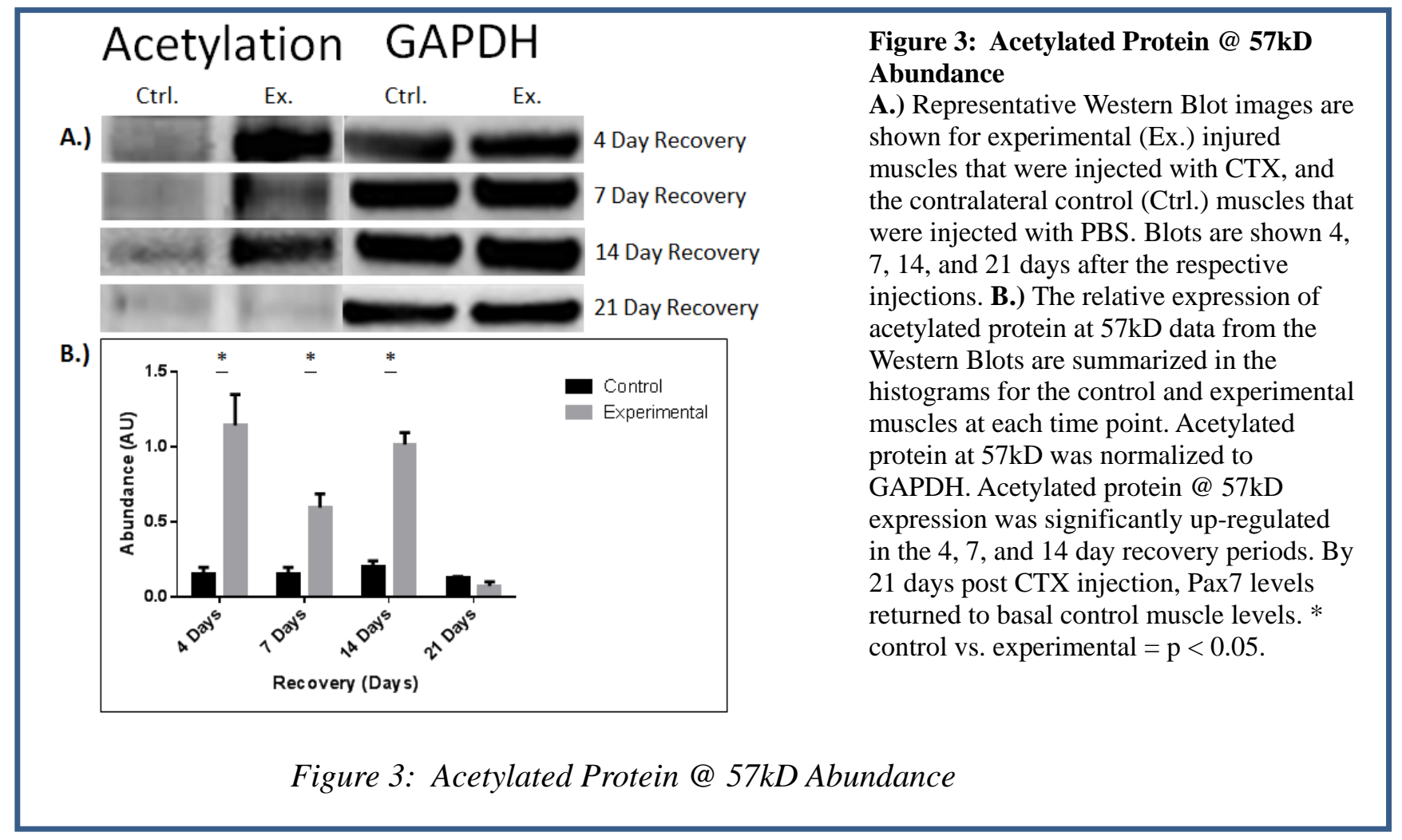

Immunoprecipitation protocols directly show the interaction between proteins. The Pax7 protein from tissue lysates was pulled-down with a Pax7 antibody and probed to determine binding partners for this protein (Appendix Figures 6-9). GCN5 was probed for and found to be directly associated with Pax7 at all time points (Figure 4). The interaction was most prominent in the 4 and 7 day recovery periods (Figure 4). This clearly demonstrates that GCN5 and Pax7 are directly bound to each other during the satellite cell mediated repair and regeneration of skeletal muscle.

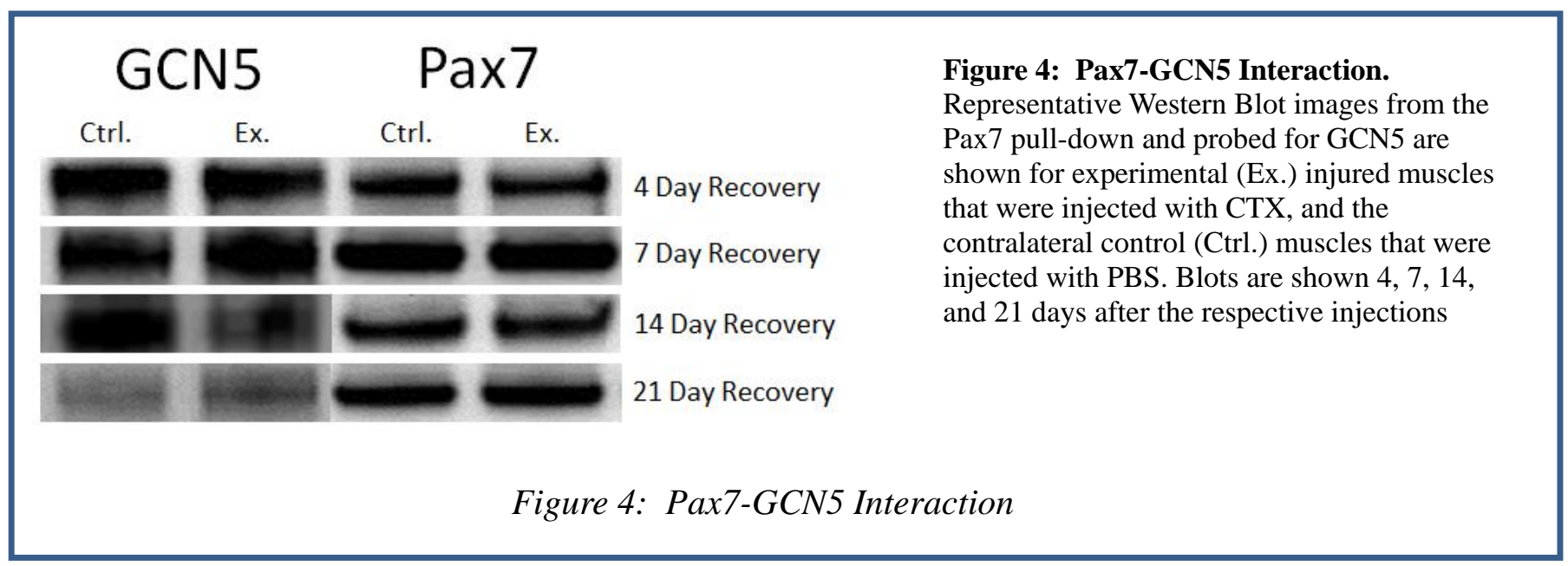


Blotting the Pax7 pull-down with the acetylated lysine antibody was used to determine the extent of Pax7 acetylation. The data show that Pax7 was acetylated, clearly showing an interaction between the acetylated lysine and the Pax7, indicating that Pax7 is acetylated. As with the IP data probed with GCN5, the acetylation of Pax 7 was most prominent in the 4 and 7 day recovery muscles (Figure 5).

\section{Acetylation $\operatorname{Pax} 7$}

Ctrl.

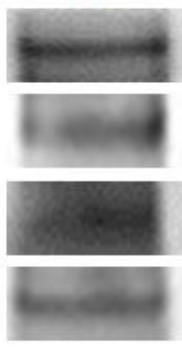

Ex.

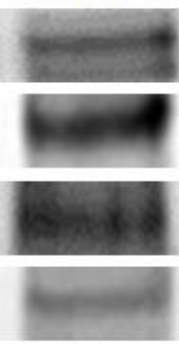

Ctrl.

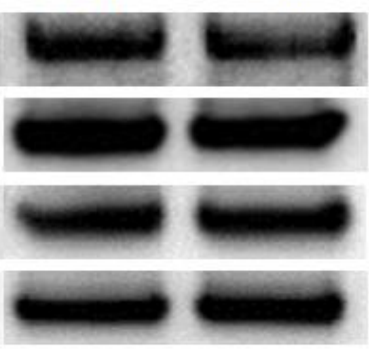

4 Day Recovery

7 Day Recovery

14 Day Recovery

21 Day Recovery
Figure 5: Pax7 Acetylation. Representative Western Blot images from the Pax7 pulldown probed for acetylation are shown for experimental (Ex.) injured muscles that were injected with CTX, and the contralateral control (Ctrl.) muscles that were injected with PBS. Blots are shown 4, 7, 14, and 21 days after the respective injections.

Figure 5: Pax7 Acetylation

To confirm that GCN5 is the acetyltransferase that is directly interacting with Pax7 in the satellite cell mediated repair and regeneration of muscle, immunohistochemical (IHC) co-localization of Pax7 and GCN5 was performed on the 4 day recovery muscles (Figure 6). There was significant damage to the muscles, illustrating the effectiveness of CTX to induce muscle injury. The data confirms that GCN5 co-localizes with the Pax $7^{+}$nuclei, further confirming the direct interaction of Pax 7 and GCN5 in the satellite cell response to muscle injury. 

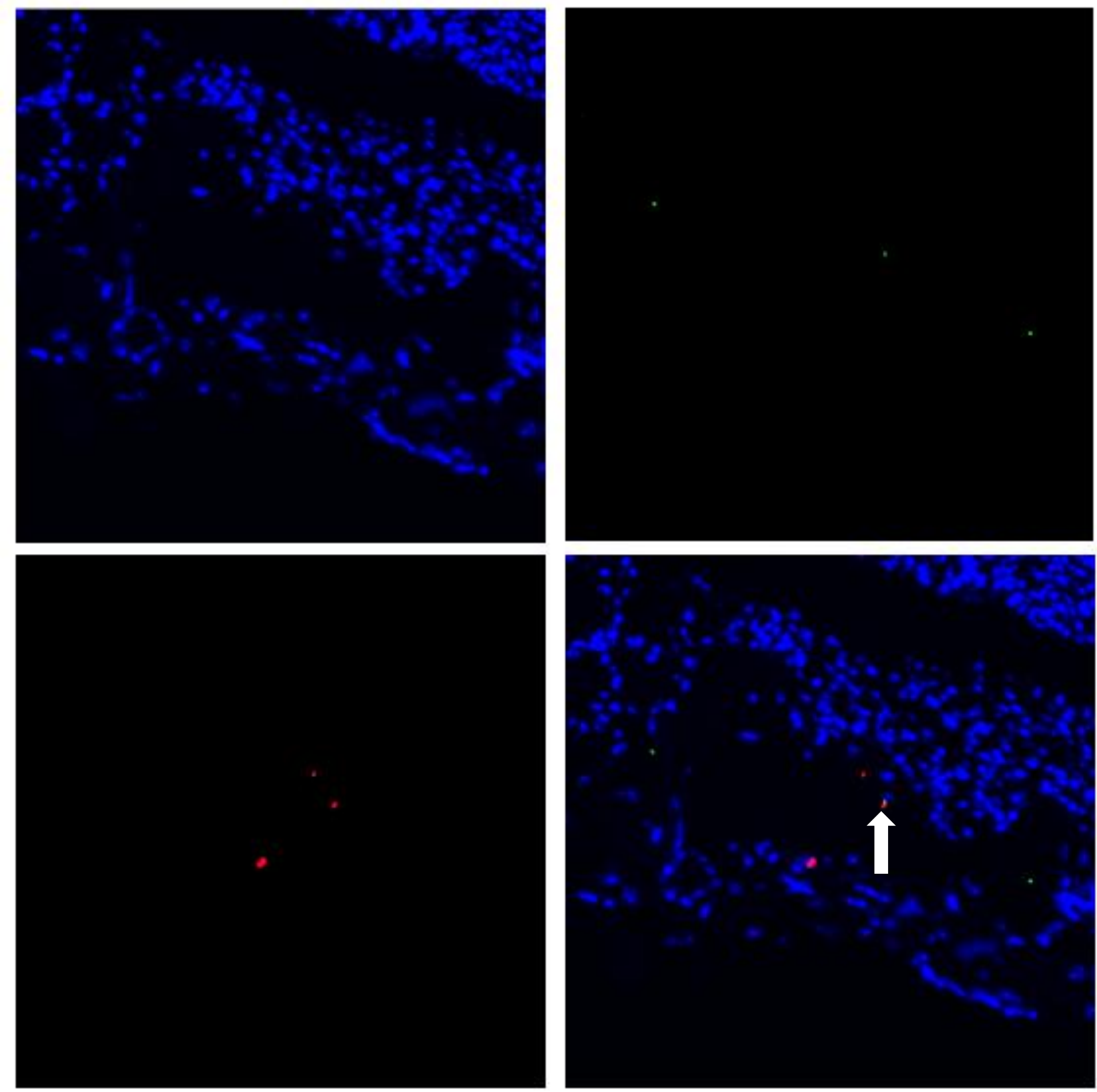

Figure 6: Pax7-GCN5 Co-localization.

Representative immunohistochemical images from co-localization of Pax7 and GCN5 4 days post CTX injection. Top left is the nuclear stain (DAPI), top right is the Pax7 stain (FITC), bottom left is the GCN5 stain (Cy3), and bottom left is the merge of all images. Pax7 and GCN5 were found to be co-localized within each other. 
The total protein abundance of Sirt1 was only significantly different between control and experimental muscles at the 14 day recovery time point with a $p=0.00074$ (Figure 7 ). This resulted in a $259.4 \%$ greater protein content compared to control muscles. However, the 7 day recovery muscles were not significant with the $\mathrm{p}=0.0887$ but had a $111.2 \%$ greater protein content compared to control muscles.

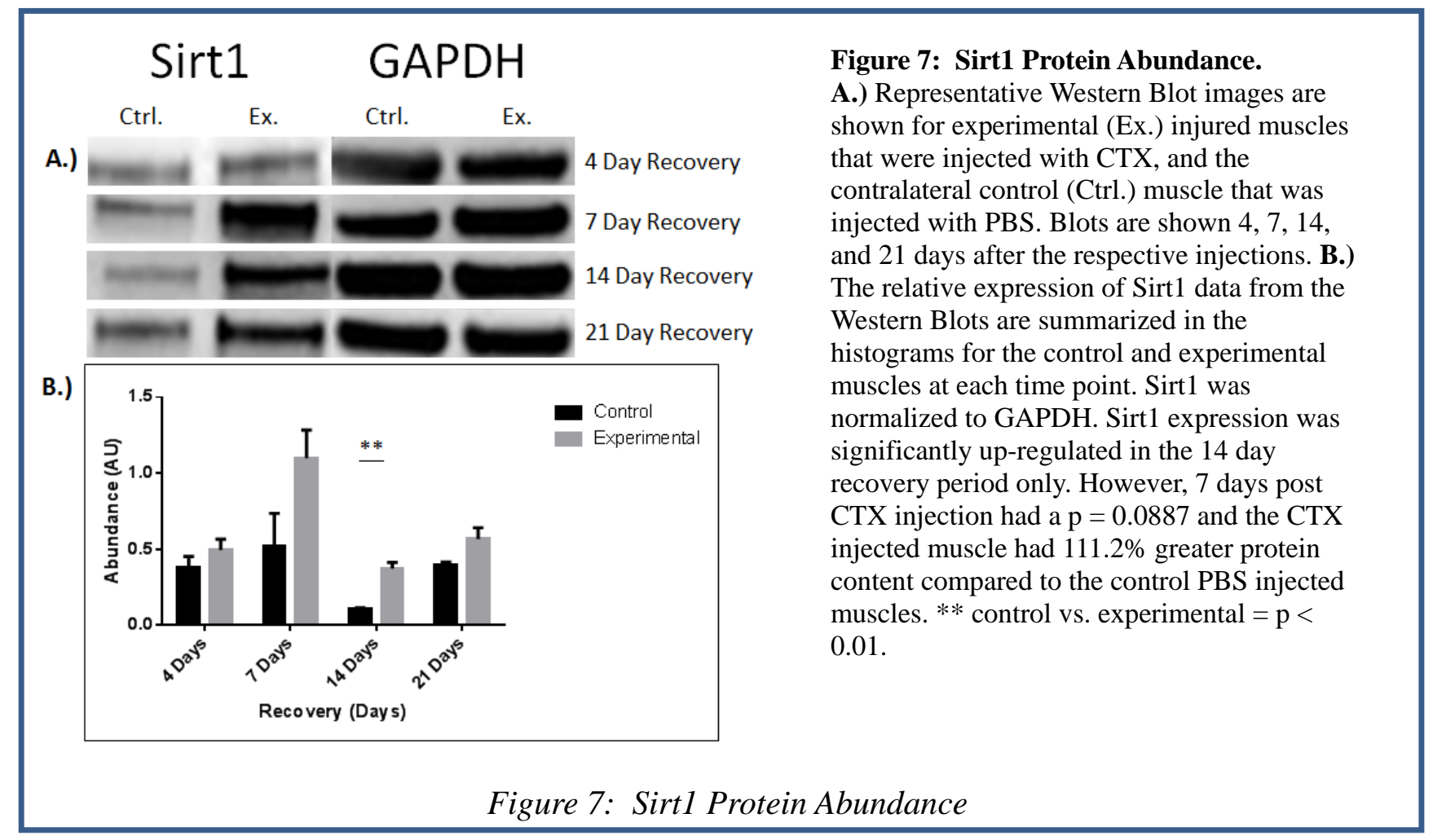

Immunoprecipitation of Pax7 was performed on all time periods and probed for Sirt1 to determine direct interaction between the two proteins (Figure 8). The Pax7-Sirt1 interaction was nonexistent at the 4 day recovery time point, but became prominent from 7 through 21 days post CTX injection (Figure 8). These data clearly demonstrate that Sirt1 is directly binding to Pax7 in the satellite cell-mediated repair and regeneration of skeletal muscle after injury. 


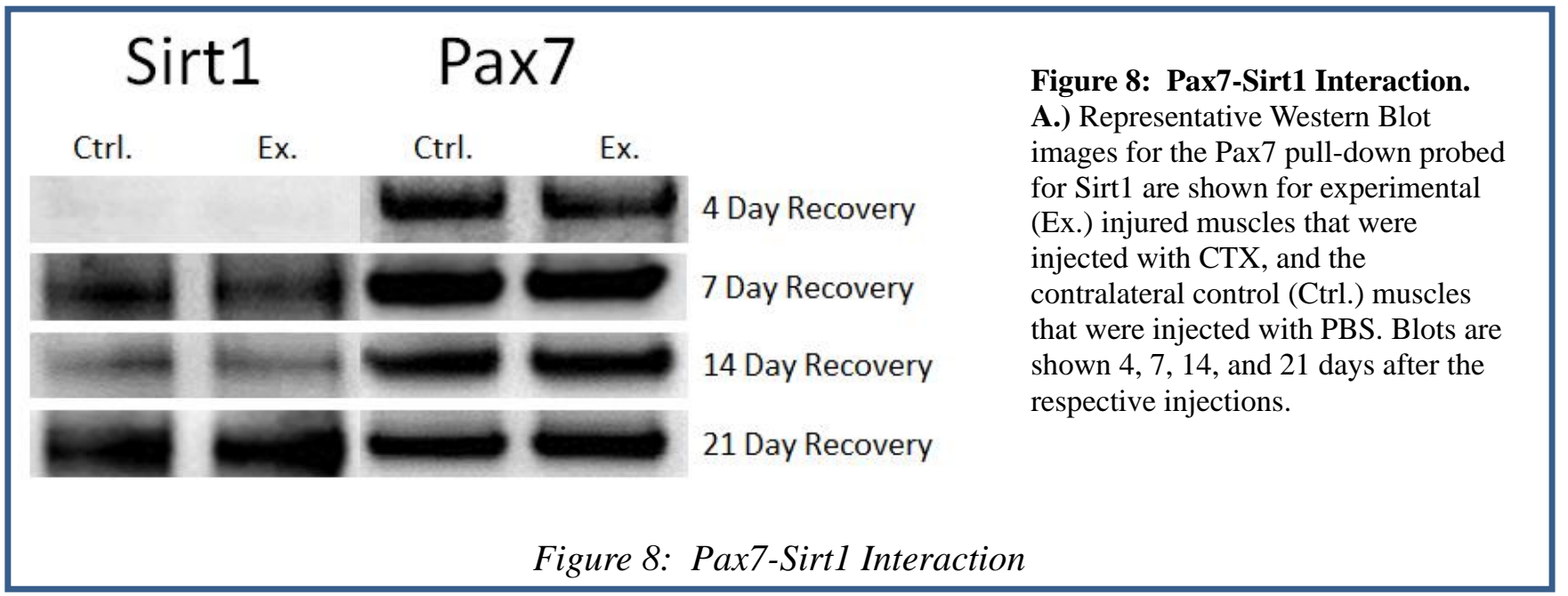

To further confirm the interaction of Pax7 with Sirt1, immunohistochemical co-localization of a FITC tagged Pax7with a Cy3 labeled Sirt1 was performed on the 14/21 days recovery muscles (Figure 9). There was a distinct co-localization of Pax7 and Sirt1, further confirming that Sirt1 directly binds and interacts with Pax7 in differentiating satellite cells. 

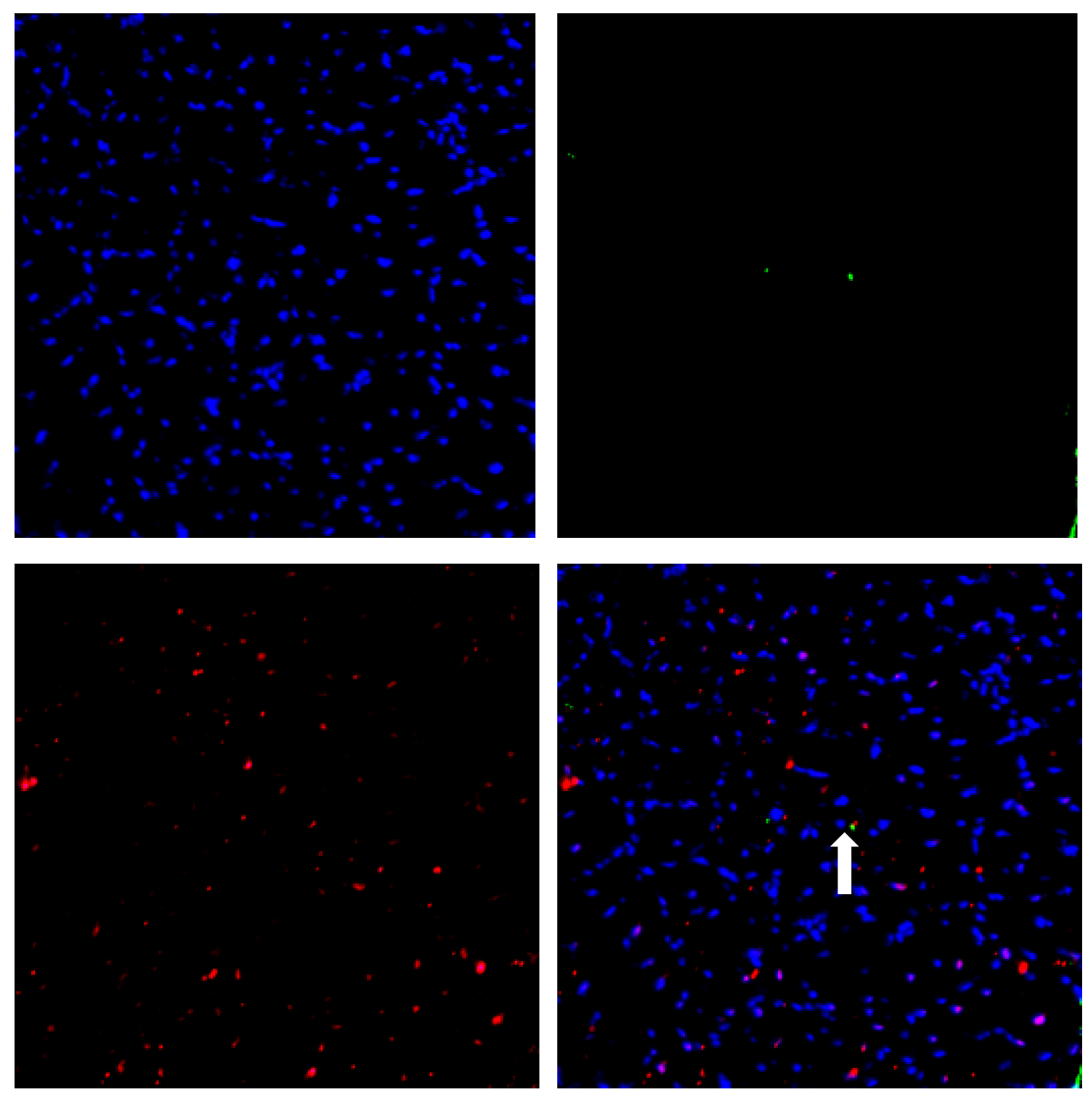

Figure 9: Pax7-Sirt1 Co-localization.

Representative immunohistochemical images from co-localization of Pax7 and Sirt1 14 days post CTX injection. Top left is the nuclear stain (DAPI), top right is the Pax7 stain (FITC), bottom left is the Sirt1 stain (Cy3), and bottom left is the merge of all images. Pax7 and Sirt1 were found to be co-localized within each other. 


\section{Discussion}

The modulation of Pax7 through post-translational modifications in regenerating skeletal muscle is largely unknown. In the current study we show novel data that Pax7 acetylation and the Pax7-Sirt1 and Pax7-GCN5 bindings are altered in satellite cells during regeneration of skeletal muscle. Data from this study supports the hypothesis that Pax7 is influenced by the acetylation status. The data clearly support the hypothesis that in the regeneration process, the activation and proliferation of satellite cells are mediated by the acetylation of Pax7 by the acetyltransferase GCN5. The data also support the hypothesis that the differentiation of myogenic-committed cells is mediated by the deacetylation of Pax7 by the deacetylase Sirt1.

\section{GCN5 Activates Pax7 by Acetylation}

Pax7 is the canonical biomarker for satellite cells and its expression is dramatically upregulated upon muscle injury ${ }^{1-4}$. Using Western Blot analysis to determine protein content from 4-21 days post injection, we were able to illustrate Pax7 expression through the various stages of muscle regeneration (Figure 1). Four days post injection of CTX into the TA indicates the early injury phase and should correspond to significant activation of satellite cells, resulting in dramatic up-regulation of $\operatorname{Pax}^{+}$cells. As demonstrated in Figure 1, 4 days of recovery after CTX injury resulted in significant up-regulation of $\operatorname{Pax} 7(\mathrm{p}=0.003)$. This corresponded to a 592.2\% greater Pax7 protein content in experimental CTX injected muscles compared to control PBS injected muscles. By 7 days post CTX injection, some of the myoblasts should have begun differentiating to regenerate the damaged muscle but the majority of activated satellite cells will continue to proliferate and provide sufficient nuclei for the regeneration process. The data show that Pax7 abundance is significantly up-regulated by $204.1 \%$ as compared to the control muscle $(\mathrm{p}=0.006) 7$ days post CTX injury (Figure 1). By 14 days post CTX injection, it would be expected to see a leveling off of Pax7 protein expression, as the differentiation of myoblasts should be more prominent for the repair process. However, Pax 7 protein abundance 
remained elevated by $219.1 \%$ as compared to the control muscle $(\mathrm{p}<0.001)$ after 14 days of recovery. CTX injected muscle had regained the muscle weight and even gained mass (hypertrophied) and Pax7 protein abundance had returned to basal levels after 21 days of recovery (Appendix Table 1).

These data are consistent with numerous studies showing an increase in Pax7 abundance which reflects the satellite cell response to muscle injury ${ }^{1-4}$. Pax 7 is expressed in all quiescent and activated satellite cells, but it is dramatically up-regulated upon muscle injury as satellite cells proliferate to mediate repair and regeneration of the injured muscle ${ }^{1-4}$. Once myoblasts begin to differentiate and commit to repair the damaged muscle, Pax7 is turned off and muscle-specific transcription factors are solely expressed, such as MyoD and myogenin ${ }^{1-4}$. This is consistent with our Western Blot data, where 4 days post CTX injection resulted in 592.2\% greater Pax7 protein compared to control muscles (Figure 1). The protein abundance of Pax 7 remained significantly greater in the 7 and 14 day recovery animals ( $\mathrm{p}=0.006$ and $\mathrm{p}<0.001$, respectively) compared to controls (Figure 1). These data are consistent with the previous studies ${ }^{1-4,8}$ and is expected during the repair and regeneration process. As repair is in progress, there will be an initial and rapid increase in satellite cell numbers to prepare for the repair process. Following this initial phase, some cells will begin to differentiate and contribute nuclei to the damaged muscles while other satellite cells will continue to proliferate. This corresponds to the 7 and 14 day recovery muscles where Pax 7 was significantly lower compared to the 4 day recovery muscles $(\mathrm{p}<0.05)$; however, Pax7 was still significantly greater than the corresponding control muscles (Figure 1). Complete repair and regeneration of damaged muscles corresponded to a return of Pax7 to basal levels, since presumably the muscles no longer need to maintain a high level of proliferation of satellite cells to repair damage ${ }^{1-4}$. Twenty-one days after the CTX injection, the muscles were completely repaired and had even hypertrophied relative to the control muscles (Appendix Table 1). As expected, the corresponding Western Blots also show that Pax7 abundance had returned to basal control levels in the repaired muscles 21 days post injury. 
While it is known that Pax7 is expressed in quiescent, activated, and proliferating satellite cells, the modifications to Pax7 itself are largely unknown in the satellite cell signaling cascade. Our preliminary data suggested that the acetyltransferase GCN5 associated with Pax7 during the satellite cell response to muscle injury. To follow-up these observations, GCN5 was studied using Western Blots. We found that 4 days post CTX injury, GCN5 protein content was significantly up-regulated (p < 0.01) in the experimental muscle compared to the control muscles but the abundance of GCN5 decreased after this time point (Figure 2). These data are consistent with the idea that GNC5 is an important regulator of satellite cell proliferation (e.g., at day 4), but is less important during maturation and differentiation of the activated satellite cells (e.g., days 14 and 21).

Since GCN5 is an acetyltransferase that is hypothesized to be acting on Pax7 in the satellite cell mediated repair and regeneration of injured muscle, we decided to test for acetylated protein in the Western Blot data. Although we recognize that the antibody to identify acetylated lysine is not-specific for Pax7, we stripped the Pax7 membrane and re-probed it for acetylated lysine as an indicator of the total acetylated protein in the Pax7 range of 57kD. Correspondingly, we have interpreted the change in acetylated protein at $57 \mathrm{kD}$ to be indicative of Pax7 acetylation. Our data show that acetylation at $57 \mathrm{kD}$ (i.e., Pax7) was elevated during the early points of satellite cell proliferation (e.g., days 4-14) but declined during the period when differentiation rather than proliferation would be the dominant signal (Figure 3). These observations are consistent with the hypothesis that GCN5 was active to acetylate and activate Pax7 in the early points of repair, and this corresponded to satellite cell activation, whereas in later periods of repair, $\operatorname{Pax} 7$ acetylation decreased (or deacetylation increased) to deactivate Pax7.

\section{Pax7 is a binding partner of GCN5 during muscle repair.}

Our immunoprecipitation data show that GCN5 directly interacted with Pax7 (Figure 4). Although GCN5 was found to be associated with Pax7 at all time points (4-21 days post CTX injection), the abundance of GCN5:Pax7 binding was not different in control and experimental legs at 
any time point. Together with the western blot data, these novel finding suggest that there is more GCN5 protein in injured muscles (Figure 2) and that GCN5 is directly interacting with Pax7 throughout the repair process (Figure 4). These findings provide support for the idea that GCN5 is up-regulated an important direct activator of Pax7.

Pax7 was acetylated at all time points (Figure 5). While Pax7 acetylation was somewhat elevated at day 4, corresponding to the period where proliferation of satellite cells would be high as compared to later time points, additional experiments are needed to clarify if Pax7 acetylation occurs transiently during the early periods surrounding CTX injury. Nevertheless, our immunoprecipitation assays provide evidence to support the hypothesis that GCN5 acetylates Pax7 to activate and proliferate satellite cells. Nevertheless, we recognize that there is some variability in GCN5:Pax7 abundance even in control muscles. One potential explanation of this is that GCN5 is already complexed with Pax7 in satellite cells under basal conditions. This is unlikely though because when IP data is compared to the Western Blot data, it would be expected that Pax7 in control muscles would be less abundant in the IP. This was not the case as the control and experimental samples in the IP yielded the same abundance. The second possibility is that satellite cells from uninjured muscles will activate and proliferate for the purpose of migrating to the CTX damaged contralateral limb. This is also unlikely because if this were the case, we would expect that the Western Blot data would show an increase in Pax7 protein abundance in the control muscles but this was not the case. A third and most likely possibility is that there was mild physical damage and inflammation to the muscle in response to the PBS injection and this might be compounded by a systemic "leak" of CTX from the injured muscle to the circulation, thereby affecting the contralateral muscle. If this is true, this might be enough of a signal to increase GCN5 without increasing Pax7 protein abundance. To test this possibility, we conducted new experiments on cage controls animals that corresponded to 4, and 14 days of normal cage activity, PBS only injected animals, and CTX only injected animals (Supplemental Figure 1) which suggests that PBS may have an effect although the muscles were not injured. 


\section{Comparison of Pax7 Pull-Downs}

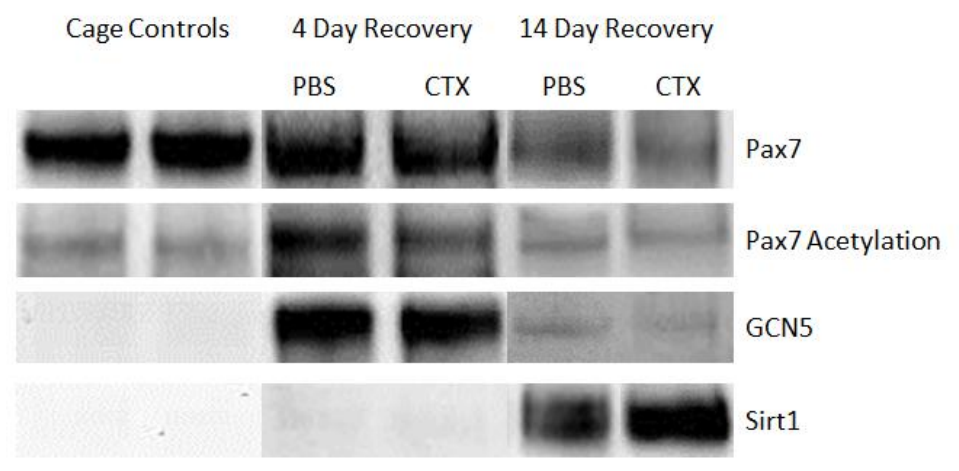

Supplementary Figure 1:

Pax7 IP Comparison

Representative Western Blot images of the immunoprecipitation of $\operatorname{Pax} 7$ at various times and treatments during skeletal muscle repair and regeneration.

Supplementary Figure 1: Comparison of Pax7 Pull-Downs

Our immunohistochemical (IHC) data confirm that GCN5 co- co-localizes with the Pax7 $7^{+}$ nuclei (Figure 6). Although we do not know if other acetyltransferases are involved in regulating Pax7, together our data strongly support the hypothesis that the acetyltransferase GCN5 activates Pax7 by acetylation in the satellite cell mediated repair and regeneration of injured skeletal muscle.

\section{Sirt1 Deactivates Pax7 by Deacetylation}

As our data supported a role for GCN5 acetylation to activate Pax7 in satellite cells, we then strove to answer the next question, which protein deactivates Pax7. Logically, if Pax 7 is activated by acetylation then it should be deactivated by a deacetylase. Our laboratory has had a long standing interest in the deacetylase Sirt1 and activators of this protein which may have several roles in skeletal muscle regeneration and aging ${ }^{40-43}$ and we chose to examine the potential that Sirt 1 could deacetylate Pax7. As previous data showed Sirt1, a NAD ${ }^{+}$dependent histone deacetylase, is involved in the satellite cell mediated repair and regeneration of skeletal muscle after injury ${ }^{29,30}$ and Sirt1 maintains MyoD in the deacetylated state to inhibit MyoD transcription preventing differentiation of myoblasts ${ }^{29,38}$, Sirt1 was of particular interest and a strong candidate.

The initial phase of injury ( $4 \& 7$ day recovery points), the levels of Sirt1 protein, which was 
likely important to maintain MyoD in the deacetylated state to prevent myoblast differentiation, were increased. After this initial phase, Sirt1 protein content was declined (Figure 7, 14 day recovery) that presumably also allowed MyoD-mediated transcription for myoblast differentiation. By 21 days post injury, Sirt1 protein levels return to the basal control levels and this would decrease the deacetylation of Pax7 (Figure 8) as the muscle has been repaired and regenerated following CTX injury.

GCN5 was strongly associated with Pax7 in the early points of regeneration (Figure 4) and significantly decreases with time $(\mathrm{p}<0.001)$ as repair and regeneration/myoblast differentiation occurs. In contrast, the deacetylase Sirt1 becomes more strongly associated with Pax7 (presumably to deactivate it) as the myoblasts are differentiating. We confirmed the Pax7-Sirt1 interaction (Figure 9) when satellite cells are primarily differentiating. This evidence along with the IP data strongly support the hypothesis that Sirt1 directly binds and interacts with Pax7 to deacetylate and deactivate the transcription factor during the satellite cell mediated repair and regeneration of muscle injury. Our IHC data (Figure 9) confirm the Pax7-Sirt1 co-localization. This evidence along with the IP data strongly support the hypothesis that Sirt1 directly binds and interacts with Pax7 to deacetylate and deactivate the transcription factor during the satellite cell mediated repair and regeneration of muscle injury.

\section{Conclusions}

In this study we show for the first time that the post-translational modifications of Pax7 in satellite cells in regenerating skeletal muscle involve GCN5, an acetyltransferase, which directly binds to and acetylates Pax7 to activate and initiate proliferation of satellite cells. Although further investigations are needed to determine the extent, necessity, or sufficiency of GCN5 in satellite cells, the data supports the hypothesis that GCN5 is a binding partner of Pax7 and is acting on Pax7 via acetylation, leading to satellite cell activation and proliferation. Sirt1, a histone deacetylase, was also found to be directly acting on Pax7 in the satellite cell signaling cascade. In this novel finding, Sirt1 was directly bound to Pax7 to deacetylate and presumably deactivate Pax7. The data supports the 
hypothesis that Sirt1 is a binding partner of Pax7 and is acting on Pax7 via deacetylation, leading to myoblast differentiation. Further experiments are needed to confirm if Sirt1 part of the deactivation network of Pax7 in regenerating muscle. 
References

1. Yin, H., Price, F. \& Rudnicki, M. A. Satellite cells and the muscle stem cell niche. Physiol. Rev. 93, 23-67 (2013).

2. Kuang, S., Kuroda, K., Grand, F. L. \& Rudnicki, M. A. Asymmetric Self-Renewal and Commitment of Satellite Stem Cells in Muscle. Cell 129, 999-1010 (2007).

3. Fujimaki, S. et al. Intrinsic Ability of Adult Stem Cell in Skeletal Muscle: An Effective and Replenishable Resource to the Establishment of Pluripotent Stem Cells. Stem Cells Int. 2013, (2013).

4. Schultz, E. Satellite cell proliferative compartments in growing skeletal muscles. Dev. Biol. 175, 84-94 (1996).

5. Dominy Jr., J. E. et al. The Deacetylase Sirt6 Activates the Acetyltransferase GCN5 and Suppresses Hepatic Gluconeogenesis. Mol. Cell 48, 900-913 (2012).

6. Snow, M. H. Myogenic cell formation in regenerating rat skeletal muscle injured by mincing II. An autoradiographic study. Anat. Rec. 188, 201-217 (1977).

7. Schultz, E., Gibson, M. C. \& Champion, T. Satellite cells are mitotically quiescent in mature mouse muscle: An EM and radioautographic study. J. Exp. Zool. 206, 451-456 (1978).

8. McKinnell, I. W. et al. Pax7 activates myogenic genes by recruitment of a histone methyltransferase complex. Nat. Cell Biol. 10, 77-84 (2008).

9. Zammit, P. S. et al. Muscle satellite cells adopt divergent fates: a mechanism for self-renewal? J. Cell Biol. 166, 347-357 (2004).

10. Hu, P., Geles, K. G., Paik, J.-H., DePinho, R. A. \& Tjian, R. Codependent Activators Direct Myoblast-Specific MyoD Transcription. Dev. Cell 15, 534-546 (2008).

11. Nagy, Z. \& Tora, L. Distinct GCN5/PCAF-containing complexes function as co-activators and are involved in transcription factor and global histone acetylation. Oncogene 26, 5341-5357 (2007).

12. Marmorstein, R. \& Roth, S. Y. Histone acetyltransferases: function, structure, and catalysis. Curr. 
Opin. Genet. Dev. 11, 155-161 (2001).

13. Brownell, J. E. \& Allis, C. D. Special HATs for special occasions: linking histone acetylation to chromatin assembly and gene activation. Curr. Opin. Genet. Dev. 6, 176-184 (1996).

14. Roth, S. Y., Denu, J. M. \& Allis, C. D. Histone Acetyltransferases. Annu. Rev. Biochem. 70, 81-120 (2001).

15. Carrozza, M. J., Utley, R. T., Workman, J. L. \& Côté, J. The diverse functions of histone acetyltransferase complexes. Trends Genet. 19, 321-329 (2003).

16. Yang, X.-J., Ogryzko, V. V., Nishikawa, J., Howard, B. H. \& Nakatani, Y. A p300/CBP-associated factor that competes with the adenoviral oncoprotein E1A. Nature 382, 319-324 (1996).

17. Kuo, M.-H. et al. Transcription-linked acetylation by Gen5p of histones $\mathrm{H} 3$ and $\mathrm{H} 4$ at specific lysines. Nature 383, 269-272 (1996).

18. Schiltz, R. L. et al. Overlapping but Distinct Patterns of Histone Acetylation by the Human Coactivators p300 and PCAF within Nucleosomal Substrates. J. Biol. Chem. 274, 1189-1192 (1999).

19. Grant, P. A. et al. Expanded Lysine Acetylation Specificity of Gen5 in Native Complexes. J. Biol. Chem. 274, 5895-5900 (1999).

20. Zeng, L. \& Zhou, M.-M. Bromodomain: an acetyl-lysine binding domain. FEBS Lett. 513, 124128 (2002).

21. Owen, D. J. et al. The structural basis for the recognition of acetylated histone $\mathrm{H} 4$ by the bromodomain of histone acetyltransferase Gcn5p. EMBO J. 19, 6141-6149 (2000).

22. Dhalluin, C. et al. Structure and ligand of a histone acetyltransferase bromodomain. Nature 399, 491-496 (1999).

23. Marmorstein, R. Structure of histone acetyltransferases. J. Mol. Biol. 311, 433-444 (2001).

24. $\mathrm{Xu}$, W. et al. Loss of Gen512 leads to increased apoptosis and mesodermal defects during mouse development. Nat. Genet. 26, 229-232 (2000). 
25. Yamauchi, T. et al. Distinct but overlapping roles of histone acetylase PCAF and of the closely related PCAF-B/GCN5 in mouse embryogenesis. Proc. Natl. Acad. Sci. 97, 11303-11306 (2000).

26. Lerin, C. et al. GCN5 acetyltransferase complex controls glucose metabolism through transcriptional repression of PGC-1 $\alpha$. Cell Metab. 3, 429-438 (2006).

27. Gerhart-Hines, Z. et al. Metabolic control of muscle mitochondrial function and fatty acid oxidation through SIRT1/PGC-1 $\alpha$. EMBO J. 26, 1913-1923 (2007).

28. Rodgers, J. T. et al. Nutrient control of glucose homeostasis through a complex of PGC-1 $\alpha$ and SIRT1. Nature 434, 113-118 (2005).

29. Ryall, J. G. The role of sirtuins in the regulation of metabolic homeostasis in skeletal muscle. Curr. Opin. Clin. Nutr. Metab. Care 15, 561-566 (2012).

30. Yu, J. \& Auwerx, J. The role of sirtuins in the control of metabolic homeostasis. Ann. N. Y. Acad. Sci. 1173 Suppl 1, E10-19 (2009).

31. Cantó, C. et al. AMPK regulates energy expenditure by modulating NAD+ metabolism and SIRT1 activity. Nature 458, 1056-1060 (2009).

32. Silva, J. P. \& Wahlestedt, C. Role of Sirtuin 1 in metabolic regulation. Drug Discov. Today 15, 781$791(2010)$.

33. Fulco, M. et al. Glucose restriction inhibits skeletal myoblast differentiation by activating SIRT1 through AMPK-mediated regulation of Nampt. Dev. Cell 14, 661-673 (2008).

34. Hariharan, N. et al. Deacetylation of FoxO by Sirt1 Plays an Essential Role in Mediating Starvation-Induced Autophagy in Cardiac Myocytes. Circ. Res. 107, 1470-1482 (2010).

35. Rajamohan, S. B. et al. SIRT1 promotes cell survival under stress by deacetylation-dependent deactivation of poly(ADP-ribose) polymerase 1. Mol. Cell. Biol. 29, 4116-4129 (2009).

36. Bai, P. et al. PARP-2 regulates SIRT1 expression and whole-body energy expenditure. Cell Metab. 13, 450-460 (2011).

37. Bai, P. \& Cantó, C. The Role of PARP-1 and PARP-2 Enzymes in Metabolic Regulation and 
Disease. Cell Metab. 16, 290-295 (2012).

38. Rathbone, C. R., Booth, F. W. \& Lees, S. J. Sirt1 increases skeletal muscle precursor cell proliferation. Eur. J. Cell Biol. 88, 35-44 (2009).

39. Motta, M. C. et al. Mammalian SIRT1 represses forkhead transcription factors. Cell 116, 551-563 (200).

40. Jackson, J. R., Ryan, M. J. \& Alway, S. E. Long-Term Supplementation With Resveratrol Alleviates Oxidative Stress but Does Not Attenuate Sarcopenia in Aged Mice. J Gerontol A Biol Sci Med Sci 66А, 751-764 (2011).

41. Jackson, J. R., Ryan, M. J., Hao, Y. \& Alway, S. E. Mediation of endogenous antioxidant enzymes and apoptotic signaling by resveratrol following muscle disuse in the gastrocnemius muscles of young and old rats. AJP: Regulatory, Integrative and Comparative Physiology 299, R1572-R1581 (2010).

42. Durbin, S. M. et al. Resveratrol supplementation preserves long bone mass, microstructure, and strength in hindlimb-suspended old male rats. J Bone Miner Metab 32, 38-47 (2014).

43. Ryan, M. J. et al. Suppression of Oxidative Stress by Resveratrol After Isometric Contractions in Gastrocnemius Muscles of Aged Mice. J Gerontol A Biol Sci Med Sci 65A, 815-831 (2010). 


\title{
Chapter 5-Findings, Limitations, \& Future Research
}

\author{
Specific Aim \#1
}

Specific Aim \#1 was to determine if GCN5 was a binding partner of Pax7 and acts on Pax7 via acetylation. In our research, we approached this by designing the experimental protocol to observe the satellite cell mediated repair and regeneration of skeletal muscle from initial injury through complete regeneration. To provide enough damage to ensure that we had enough samples, a cardiotoxin (CTX) was injected into the tibialis anterior of mice. The mice were then allowed 4, 7, 14, or 21 days to recover from the CTX injection and provided appropriate time points to observe the complete satellite cell mediated repair and regeneration. Western Blot was then utilized to examine several proteins through the repair and regeneration process. Proteins being probed for included: Pax7, Sirt1, Sirt6, GCN5, and acetylated protein in Pax7's molecular range of 57kD.

The 4 and 7 day Western Blots were of particular interest for the first aim, as the CTX injection would cause a massive amount of damage and result in satellite cell activation and proliferation. As expected, the damage to the muscles was extensive and resulted in a strong satellite cell response. This was evident in the significant up-regulation of Pax7 protein abundance in the CTX injected muscles compared to the control muscles in both the 4 and 7 day recovery animals. In support of the hypothesis that GCN5 is acting on Pax7, GCN5 protein abundance was also found to be significantly up-regulated in the 4 and 7 day recovery animals. If GCN5 is resulting in the acetylation of Pax7, it would be expected that Pax7 is acetylated. While Western Blot analysis does not directly show interaction, it was necessary to test for acetylation in the Pax7 molecular range of $57 \mathrm{kD}$ before going any further into the investigation. We found that in the $57 \mathrm{kD}$ range, there was significant up-regulation of acetylated protein in the 4 and 7 day recovery animals. With this evidence supporting the hypothesis of the first aim, additional experimentation could be performed to further test the hypothesis. 
Immunoprecipitation (IP) of Pax7 was then conducted to show direct interaction of proteins. Pax7 was pulled-down and probed for GCN5 to show direct interaction between the proteins. In support of the hypothesis, we found that GCN5 was in fact directly bound to Pax7 in the 4 and 7 day recovery mice. To provide further support that GCN5 is acetylating Pax7, the Pax7 membrane from the IP was stripped and probed for acetylation. It was found that Pax 7 was in fact acetylated in both the 4 and 7 day recovery animals. This evidence supports the hypothesis that GCN5 is acetylating Pax7 to activate and proliferate satellite cells.

To provide further support of the hypothesis, immunohistochemical experimentation was conducted on the 4 day recovery muscles to co-localize Pax 7 and GCN5 within the nuclei of regenerating muscle. Since $\operatorname{Pax} 7$ is a nuclear transcription factor that is the canonical biomarker for activated and proliferating satellite cells, the co-localization of GCN5 would confirm the IP data that GCN5 directly binds and acetylates Pax7 in the satellite cell mediated repair and regeneration of skeletal muscle. It was found that GCN5 and Pax7 were co-localized within the nuclei of regenerating muscle.

The evidence supports the hypothesis that GCN5 acetylates Pax7, resulting in the activation and proliferation of satellite cells in the regeneration of muscle. However, there are some limitations that prevent the absolution of the claim. The control muscle IP data is not convincing of the necessity or sufficiency of GCN5 or acetylation as a means for the Pax7-mediated repair and regeneration of skeletal muscle; it would be expected that the experimental blots would have significantly greater abundance of protein compared to the control blots rather than the same abundance. One potential explanation of this is that GCN5 is already complexed with Pax7 in satellite cells and resulting in no real changes when an IP is performed. This is unlikely though because when IP data is compared to the Western Blot data, it would be expected that Pax7 in control muscles would be less abundant in the IP. This was not the case as the control and experimental samples in the IP yielded the same abundance. The second possibility for this could be a result of the presence of activated satellite cells; it has been 
illustrated that satellite cells from uninjured muscles will activate and proliferate followed by mobilization to a damaged area to aid in the repair and regeneration process. This is also unlikely because the Western Blot data would show an increase in Pax7, which was not the case. A third and most likely possibility is that there was physical damage from the needle and inflammation damage to the muscle during the PBS injection. This would result in damage that would not necessarily be apparent in the Western Blot, but would be during the IP due to its specificity for the pulled-down protein. To test this possibility, we conducted new experiments on cage controls animals that corresponded to 4, and 14 days of normal cage activity, PBS only injected animals, and CTX only injected animals (Supplemental Figure 1) which data suggests that PBS may have an effect although the muscles were not injured.

The second limitation of this study is that no other proteins were used for the IP. To truly confirm GCN5 interaction of Pax7, GCN5 needs to be pulled down as well and probed for Pax7 and acetylation. This was planned to be performed, but the $-80^{\circ} \mathrm{C}$ freezer where the samples were stored went out over one weekend and ruined all the samples before additional experimentation could be performed. However, with the new experimental protocol using cage controls to determine if the PBS control injections are truly representative of control muscles, this will allow for IP's to be performed to address this issue.

A third limitation in determining the necessity of GCN5 in the activation of Pax7 in satellite cells is the lack of a transgenic mouse model. The complete ablation of GCN5 in a mouse with the established experimental protocols would certainly shed new light and enable concrete claims. An alternative or compliment to transgenic models would have been to isolate quiescent satellite cells from mice and treat them with GCN5 and see if proliferation occurred. Treating with GCN5 and observing rapid proliferation would allow for conclusions to be made. Using other acetyltransferases on the isolated satellite cells could determine if any acetyltransferase could accomplish the activation and proliferation and determine if GCN5 is part of the activation/deactivation process in satellite cells. 
Future work needs to be performed using both transgenic mouse models along with the isolation and culture of satellite cells to be treated with GCN5. This will allow for definitive conclusions to be made about the role of GCN5 in the activation and proliferation of satellite cells. Furthermore, additional IP's using more than just a Pax7 pull-down need to be performed.

\section{Specific Aim \#2}

The second aim of this study was to determine if Sirt1 was a binding partner of Pax7 and acts on Pax7 by deacetylation. As with the first aim, we needed to establish the abundance of Sirt1 in the damaged muscle before attempting to show any interaction. With evidence that GCN5 is significantly up-regulated in the early phase of satellite cell mediated repair and regeneration, the 7, 14, and 21 day recovery muscles were of particular interest for the second aim.

In the 4 day recovery, we saw no statistical difference in Sirt1 protein abundance between the control versus experimental muscles. By 7 days post injection, there was a dramatic increase in abundance of Sirt1 protein, although not statistically significant. However, this resulted in $111.2 \%$ greater protein abundance as compared to control muscles. Fourteen days post CTX injection showed statistically significant greater protein abundance that resulted in $259.4 \%$ greater amount of protein. By 21 days post injection, Sirt1 protein levels returned to basal control levels. This illustrated to us that Sirt1 is most prominent during the latter stage of the satellite cell mediated repair and regeneration process. This did not show interaction of any kind with Pax7, but was necessary to see when Sirt1 was most abundant.

With Sirt1 shown to be most prominent in the 7 and 14 day recovery muscles, we then used IP to determine if Sirt1 is physically binding to $\operatorname{Pax} 7$ at any time during the repair and regeneration process. As expected, there was almost no binding of Sirt1 to Pax 7 after 4 days of recovery. By 7 days post CTX injection, there was significant binding of Sirt1 to Pax7, which was a novel finding since it 
has not been established that Sirt1 binds to Pax7. We also found that Sirt1 was bound to Pax7 in the 14 and 21 day recovery muscles. These data support the hypothesis that Sirt1 is a binding partner of Pax7. With the concomitant decrease in Pax7 acetylation, it is likely that Sirt1 is acting on Pax7 via deacetylation. However, there need to be additional experimentation to test the extent of Sirt1's involvement with Pax7.

We next used co-localization of Sirt1 and Pax 7 in the 14 day recovery muscles to further illustrate that Sirt1 is binding to Pax7. In this experimentation, we found that Sirt1 was co-localized with Pax7 within the regenerating muscles. This complimented the IP data by directly showing the colocalization of the two proteins in regenerating muscle. These data support the hypothesis that Sirt1 is a binding partner of Pax7.

While these data support the hypothesis that Sirt1 is binding to Pax7 and acting upon Pax7 via deacetylation, there were some limitations to the experimentation that prevent us from making concrete claims about Sirt1 and Pax7's interactions. The first limitation is the variable IP data. As with the GCN5 experimentation, Sirt1 was found to be just as strongly associated with Pax7 in the control muscles as it was in the experimental muscles. As stated previously, this could have been the result of satellite cell activation in the control muscles so they can migrate and aid in the repair process or, the more likely option, the PBS injection into the control muscles resulted in damage and inflammation that resulted in the activation and proliferation of the control muscles. New IP data were performed using cage controls, PBS injected only animals, and CTX injected only animals. It was found that PBS is causing an insult of some kind resulting in a satellite cell response (Supplementary Figure 1).

The second limitation of the experimentation was a lack of an IP with Sirt1 pulled down to confirm that Pax7 was bound to Sirt1. This would have provided a second confirmation of the Pax7 pull-down data. As previously stated, there was a $-80^{\circ} \mathrm{C}$ freezer malfunction which resulted in the complete loss of all the muscle samples before the Sirt1 pull-down could be performed.

A third limitation in determining Sirt1's necessity in repair and regeneration of skeletal muscle 
is the lack of a transgenic model. As previously described, this would undoubtedly provide insight into the necessity of Sirt1. The use of our conditional wild-type mice, being Sirt1 floxed without Cre expression, provides a good foundation for further research. Also as stated previously, the use of isolated satellite cells and cultured with Sirt1 and other deacetylases would determine the necessity of Sirt1 in the differentiation process.

Future research needs to address these limitations to determine Sirt1's necessity in the repair and regeneration process. The use of a transgenic model and isolated satellite cells will provide the information needed to confirm Sirt1's interaction with Pax7 in the satellite cell mediated repair and regeneration process. 
References

1. Yin, H., Price, F. \& Rudnicki, M. A. Satellite cells and the muscle stem cell niche. Physiol. Rev. 93, 23-67 (2013).

2. Kuang, S., Kuroda, K., Grand, F. L. \& Rudnicki, M. A. Asymmetric Self-Renewal and Commitment of Satellite Stem Cells in Muscle. Cell 129, 999-1010 (2007).

3. Fujimaki, S. et al. Intrinsic Ability of Adult Stem Cell in Skeletal Muscle: An Effective and Replenishable Resource to the Establishment of Pluripotent Stem Cells. Stem Cells Int. 2013, (2013).

4. Schultz, E. Satellite cell proliferative compartments in growing skeletal muscles. Dev. Biol. 175, 84-94 (1996).

5. Dominy Jr., J. E. et al. The Deacetylase Sirt6 Activates the Acetyltransferase GCN5 and Suppresses Hepatic Gluconeogenesis. Mol. Cell 48, 900-913 (2012).

6. Snow, M. H. Myogenic cell formation in regenerating rat skeletal muscle injured by mincing II. An autoradiographic study. Anat. Rec. 188, 201-217 (1977).

7. Schultz, E., Gibson, M. C. \& Champion, T. Satellite cells are mitotically quiescent in mature mouse muscle: An EM and radioautographic study. J. Exp. Zool. 206, 451-456 (1978).

8. McKinnell, I. W. et al. Pax7 activates myogenic genes by recruitment of a histone methyltransferase complex. Nat. Cell Biol. 10, 77-84 (2008).

9. Zammit, P. S. et al. Muscle satellite cells adopt divergent fates: a mechanism for self-renewal? J. Cell Biol. 166, 347-357 (2004).

10. Hu, P., Geles, K. G., Paik, J.-H., DePinho, R. A. \& Tjian, R. Codependent Activators Direct Myoblast-Specific MyoD Transcription. Dev. Cell 15, 534-546 (2008).

11. Nagy, Z. \& Tora, L. Distinct GCN5/PCAF-containing complexes function as co-activators and are involved in transcription factor and global histone acetylation. Oncogene 26, 5341-5357 (2007).

12. Marmorstein, R. \& Roth, S. Y. Histone acetyltransferases: function, structure, and catalysis. Curr. 
Opin. Genet. Dev. 11, 155-161 (2001).

13. Brownell, J. E. \& Allis, C. D. Special HATs for special occasions: linking histone acetylation to chromatin assembly and gene activation. Curr. Opin. Genet. Dev. 6, 176-184 (1996).

14. Roth, S. Y., Denu, J. M. \& Allis, C. D. Histone Acetyltransferases. Annu. Rev. Biochem. 70, 81-120 (2001).

15. Carrozza, M. J., Utley, R. T., Workman, J. L. \& Côté, J. The diverse functions of histone acetyltransferase complexes. Trends Genet. 19, 321-329 (2003).

16. Yang, X.-J., Ogryzko, V. V., Nishikawa, J., Howard, B. H. \& Nakatani, Y. A p300/CBP-associated factor that competes with the adenoviral oncoprotein E1A. Nature 382, 319-324 (1996).

17. Kuo, M.-H. et al. Transcription-linked acetylation by Gen5p of histones $\mathrm{H} 3$ and $\mathrm{H} 4$ at specific lysines. Nature 383, 269-272 (1996).

18. Schiltz, R. L. et al. Overlapping but Distinct Patterns of Histone Acetylation by the Human Coactivators p300 and PCAF within Nucleosomal Substrates. J. Biol. Chem. 274, 1189-1192 (1999).

19. Grant, P. A. et al. Expanded Lysine Acetylation Specificity of Gen5 in Native Complexes. J. Biol. Chem. 274, 5895-5900 (1999).

20. Zeng, L. \& Zhou, M.-M. Bromodomain: an acetyl-lysine binding domain. FEBS Lett. 513, 124128 (2002).

21. Owen, D. J. et al. The structural basis for the recognition of acetylated histone H4 by the bromodomain of histone acetyltransferase Gcn5p. EMBO J. 19, 6141-6149 (2000).

22. Dhalluin, C. et al. Structure and ligand of a histone acetyltransferase bromodomain. Nature 399, 491-496 (1999).

23. Marmorstein, R. Structure of histone acetyltransferases. J. Mol. Biol. 311, 433-444 (2001).

24. $\mathrm{Xu}$, W. et al. Loss of Gen512 leads to increased apoptosis and mesodermal defects during mouse development. Nat. Genet. 26, 229-232 (2000). 
25. Yamauchi, T. et al. Distinct but overlapping roles of histone acetylase PCAF and of the closely related PCAF-B/GCN5 in mouse embryogenesis. Proc. Natl. Acad. Sci. 97, 11303-11306 (2000).

26. Lerin, C. et al. GCN5 acetyltransferase complex controls glucose metabolism through transcriptional repression of PGC-1 $\alpha$. Cell Metab. 3, 429-438 (2006).

27. Gerhart-Hines, Z. et al. Metabolic control of muscle mitochondrial function and fatty acid oxidation through SIRT1/PGC-1 $\alpha$. EMBO J. 26, 1913-1923 (2007).

28. Rodgers, J. T. et al. Nutrient control of glucose homeostasis through a complex of PGC-1 $\alpha$ and SIRT1. Nature 434, 113-118 (2005).

29. Ryall, J. G. The role of sirtuins in the regulation of metabolic homeostasis in skeletal muscle. Curr. Opin. Clin. Nutr. Metab. Care 15, 561-566 (2012).

30. Yu, J. \& Auwerx, J. The role of sirtuins in the control of metabolic homeostasis. Ann. N. Y. Acad. Sci. 1173 Suppl 1, E10-19 (2009).

31. Cantó, C. et al. AMPK regulates energy expenditure by modulating NAD+ metabolism and SIRT1 activity. Nature 458, 1056-1060 (2009).

32. Silva, J. P. \& Wahlestedt, C. Role of Sirtuin 1 in metabolic regulation. Drug Discov. Today 15, 781$791(2010)$.

33. Fulco, M. et al. Glucose restriction inhibits skeletal myoblast differentiation by activating SIRT1 through AMPK-mediated regulation of Nampt. Dev. Cell 14, 661-673 (2008).

34. Hariharan, N. et al. Deacetylation of FoxO by Sirt1 Plays an Essential Role in Mediating Starvation-Induced Autophagy in Cardiac Myocytes. Circ. Res. 107, 1470-1482 (2010).

35. Rajamohan, S. B. et al. SIRT1 promotes cell survival under stress by deacetylation-dependent deactivation of poly(ADP-ribose) polymerase 1. Mol. Cell. Biol. 29, 4116-4129 (2009).

36. Bai, P. et al. PARP-2 regulates SIRT1 expression and whole-body energy expenditure. Cell Metab. 13, 450-460 (2011).

37. Bai, P. \& Cantó, C. The Role of PARP-1 and PARP-2 Enzymes in Metabolic Regulation and 
Disease. Cell Metab. 16, 290-295 (2012).

38. Rathbone, C. R., Booth, F. W. \& Lees, S. J. Sirt1 increases skeletal muscle precursor cell proliferation. Eur. J. Cell Biol. 88, 35-44 (2009).

39. Motta, M. C. et al. Mammalian SIRT1 represses forkhead transcription factors. Cell 116, 551-563 (200).

40. Jackson, J. R., Ryan, M. J. \& Alway, S. E. Long-Term Supplementation With Resveratrol Alleviates Oxidative Stress but Does Not Attenuate Sarcopenia in Aged Mice. J Gerontol A Biol Sci Med Sci 66А, 751-764 (2011).

41. Jackson, J. R., Ryan, M. J., Hao, Y. \& Alway, S. E. Mediation of endogenous antioxidant enzymes and apoptotic signaling by resveratrol following muscle disuse in the gastrocnemius muscles of young and old rats. AJP: Regulatory, Integrative and Comparative Physiology 299, R1572-R1581 (2010).

42. Durbin, S. M. et al. Resveratrol supplementation preserves long bone mass, microstructure, and strength in hindlimb-suspended old male rats. J Bone Miner Metab 32, 38-47 (2014).

43. Ryan, M. J. et al. Suppression of Oxidative Stress by Resveratrol After Isometric Contractions in Gastrocnemius Muscles of Aged Mice. J Gerontol A Biol Sci Med Sci 65A, 815-831 (2010). 


\section{Appendices}




\section{Appendix A: Additional Figures}

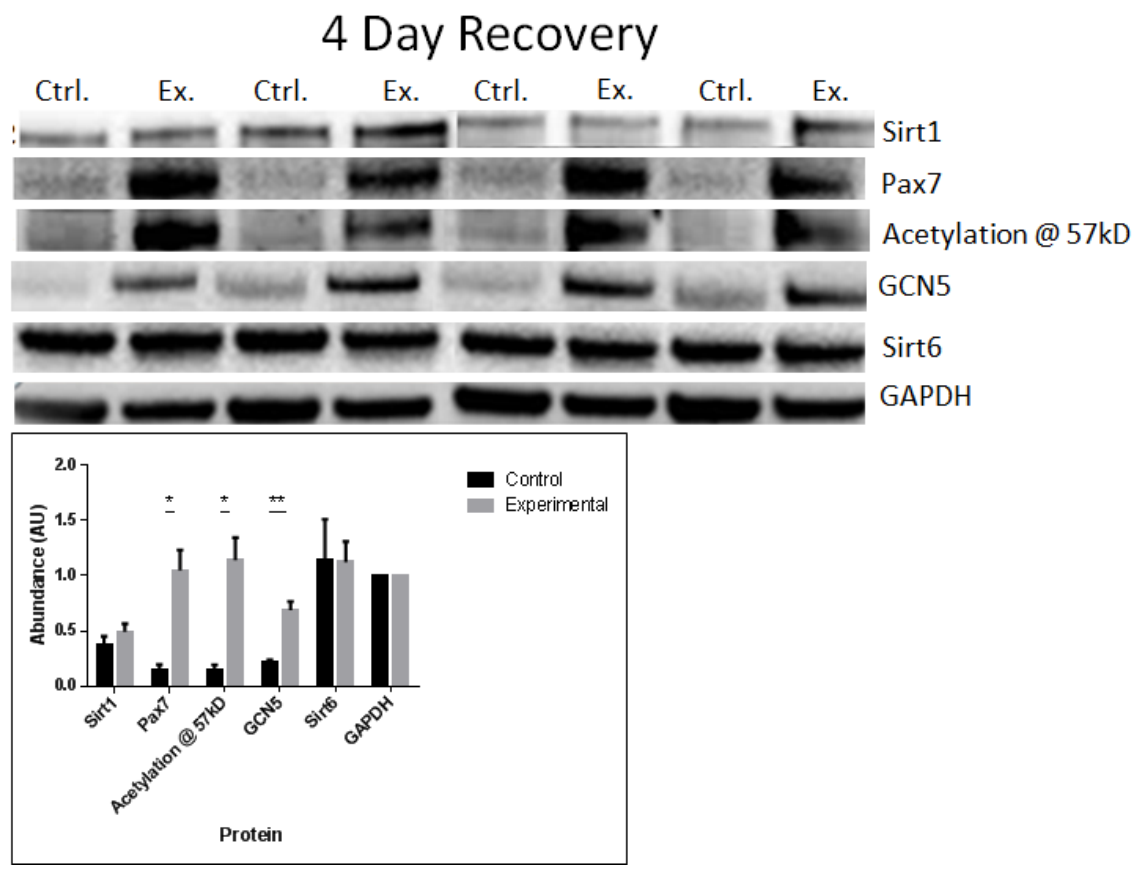

Appendix Figure 1: 4 Day Recovery Protein Abundance.

A.) Representative Western Blot images are shown for experimental (Ex.) injured muscles that were injected with CTX and the contralateral control (Ctrl.) muscles that were injected with PBS. Blots show Sirt1, Pax7, Acetylation, GCN5, Sirt6, and GAPDH proteins. B.) The relative expression of protein data from the Western Blots are summarized in the histograms at the bottom of the figure for the control and experimental muscles. The proteins are normalized to GAPDH. Pax7, Acetylated protein, and GCN5 were significantly upregulated compared to control muscles. * control vs. experimental $=\mathrm{p}<0.05 ; * *$ control vs. experimental $=p<0.01$.

\section{Appendix Figure 1: 4 Day Recovery Protein Abundance}

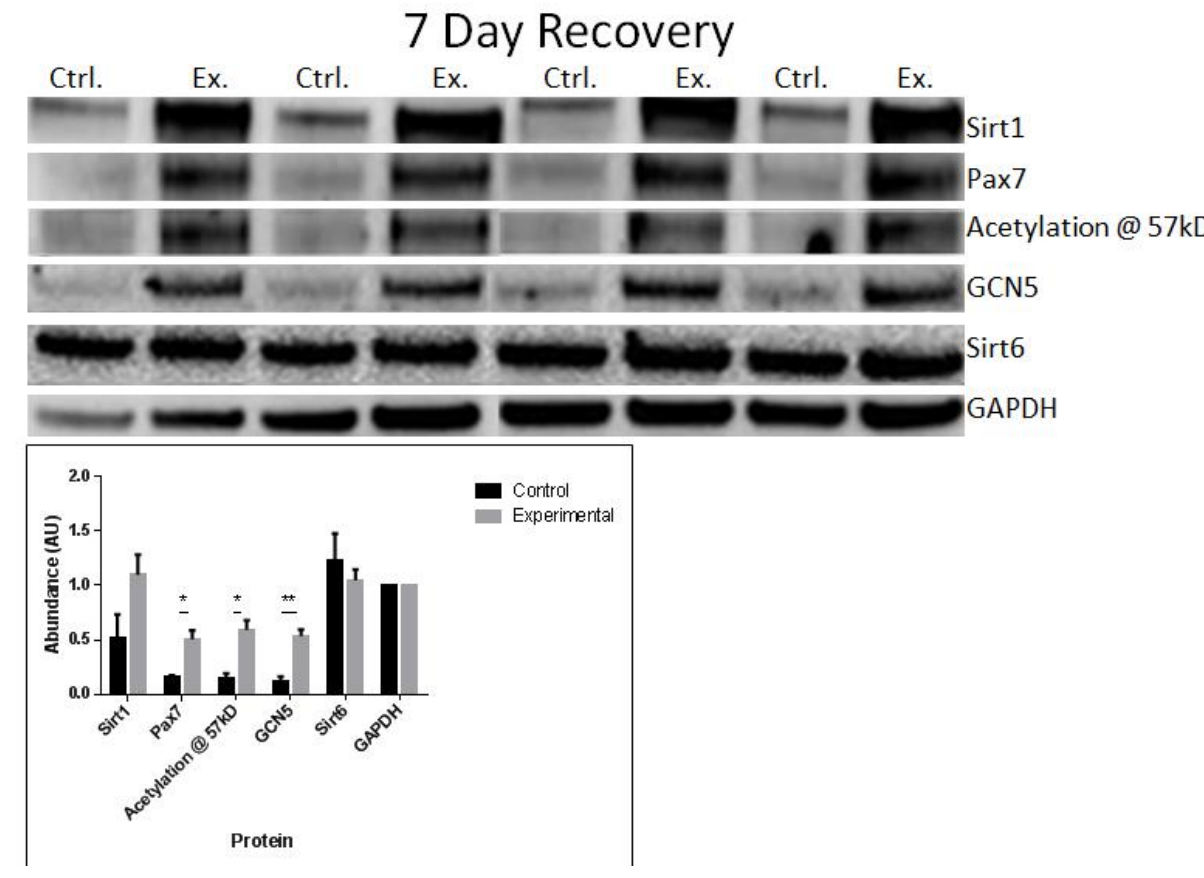

\section{Appendix Figure 2: 7 Day Recovery Protein Abundance.}

A.) Representative Western Blot images are shown for experimental (Ex.) injured muscles that were injected with CTX and the contralateral control (Ctrl.) muscles that were injected with PBS. Blots show Sirt1, Pax7, Acetylation, GCN5, Sirt6, and GAPDH proteins. B.) The relative expression of protein data from the Western Blots are summarized in the histograms at the bottom of the figure for the control and experimental muscles. The proteins are normalized to GAPDH. Pax7, Acetylated protein, and GCN5 were significantly upregulated compared to control muscles. * control vs. experimental $=\mathrm{p}<0.05 ; * *$ control vs. experimental $=\mathrm{p}<0.01$.

Appendix Figure 2: 7 Day Recovery Protein Abundance 


\section{Day Recovery}

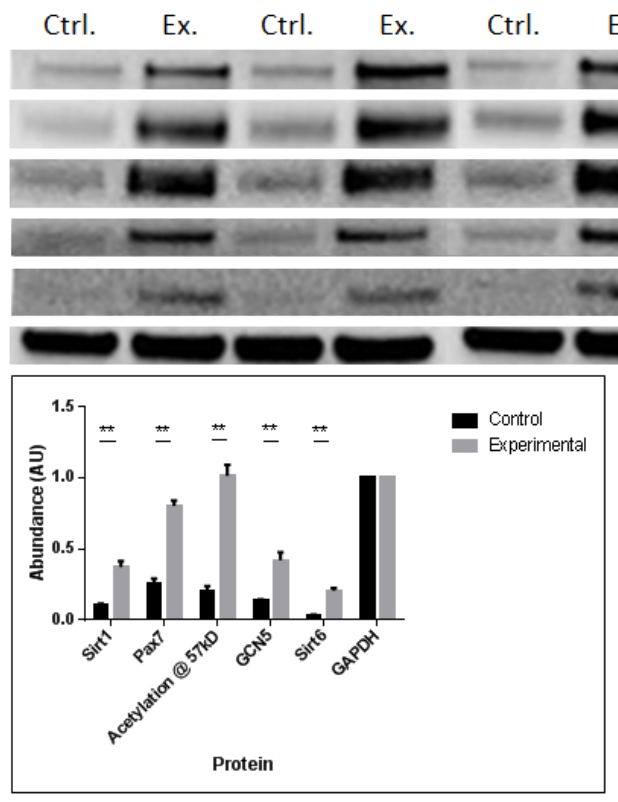

\section{Sirt1}

Pax7

Acetylation@ @ 57kD

GCN5

Sirt6

GAPDH

\section{Appendix Figure 3: 14 Day Recovery Protein Abundance}

\section{Day Recovery}

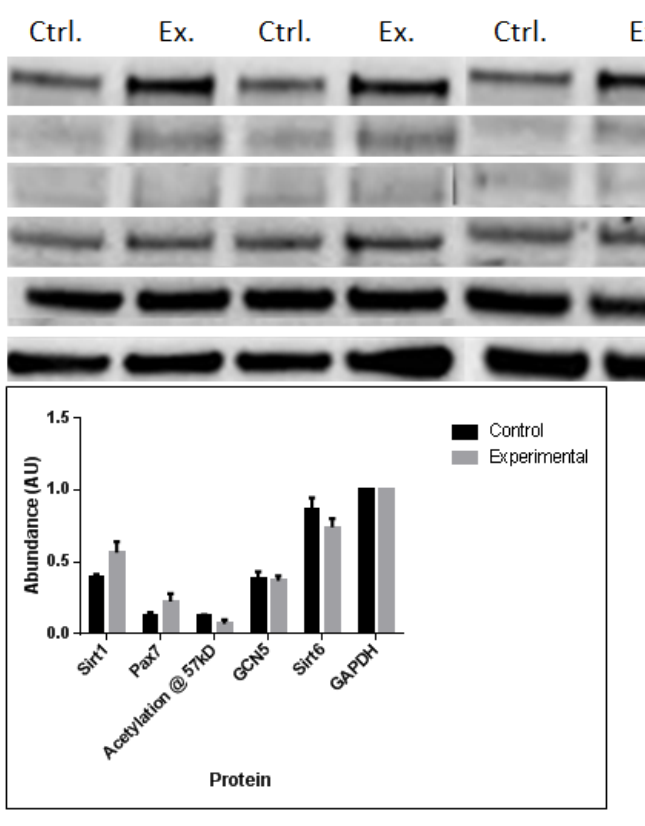

Appendix Figure 3: 14 Day Recovery Protein Abundance.

A.) Representative Western Blot images are shown for experimental (Ex.) injured muscles that were injected with CTX and the contralateral control (Ctrl.) muscles that were injected with PBS. Blots show Sirt1, Pax7, Acetylation, GCN5, Sirt6, and GAPDH proteins. B.) The relative expression of protein data from the Western Blots are summarized in the histograms at the bottom of the figure for the control and experimental muscles. The proteins are normalized to GAPDH. All proteins were significantly up-regulated compared to control muscles. $* *$ control vs. experimental $=\mathrm{p}<0.01$.

Appendix Figure 4: 21 Day Recovery Protein Abundance 


\section{Sirt6}

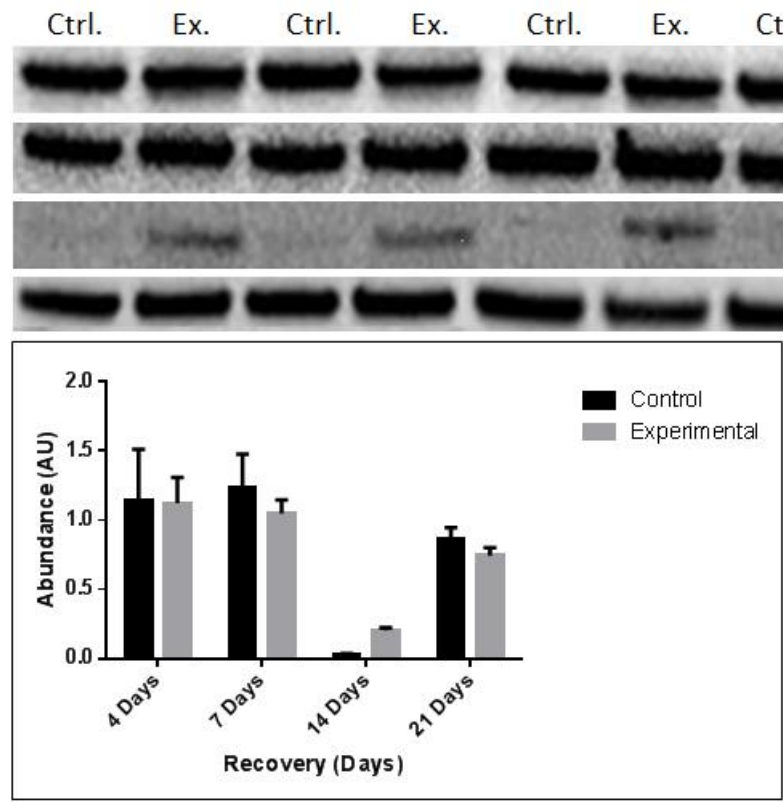

Appendix Figure 5: Sirt6 Protein Abundance
Figure 5: Sirt6 Protein Abundance.

A.) Representative Western Blot images are shown for experimental (Ex.) injured muscles that were injected with CTX and the contralateral control (Ctrl.) muscles that were injected with PBS. Blots are shown 4, 7,14 , and 21 days after the respective injections. B.) The relative expression of Sirt6 data from the Western Blots are summarized in the histograms at the bottom of the figure for the control and experimental muscles at each time point. Sirt6 was normalized to GAPDH. Sirt6 expression was not significantly different compared to control muscles at any time point.

\section{Day Recovery}

Ctrl. Ex. Ctrl. Ex. Ctrl. Ex.

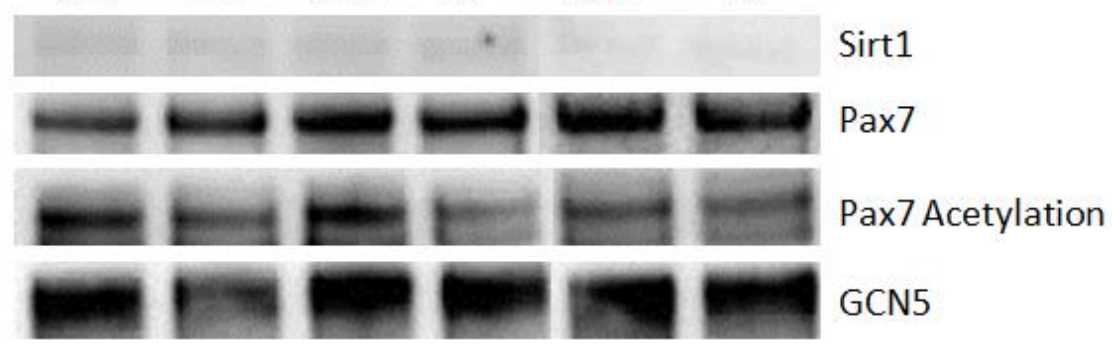

Appendix Figure 6: 4 Day Recovery Pax7 Protein Interaction
Figure 6: Pax7 Immunoprecipitation. Representative Western Blot images from the Pax7 pull-down and probed for Sirt1, Acetylation, and GCN5 are shown for experimental (Ex.) injured muscles that were injected with CTX, and the contralateral control (Ctrl.) muscles that were injected with PBS. Blots are shown for the 4 day recovery.

\section{Day Recovery}

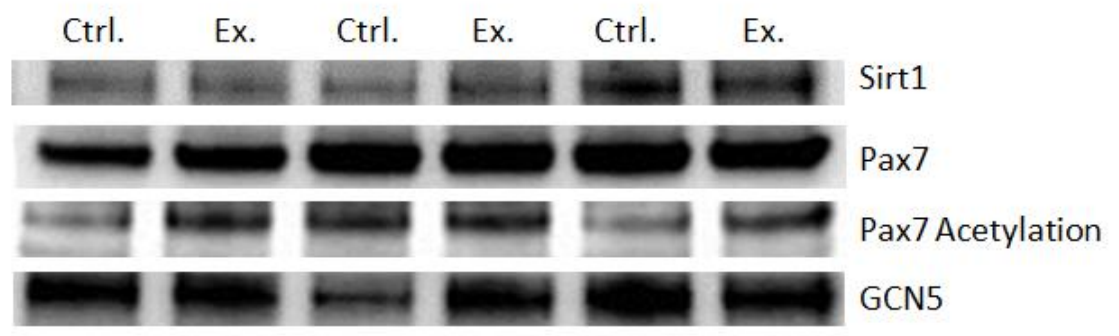

Figure 7: Pax7 Immunoprecipitation. Representative Western Blot images from the Pax7 pull-down and probed for Sirt1, Acetylation, and GCN5 are shown for experimental (Ex.) injured muscles that were injected with CTX, and the contralateral control (Ctrl.) muscles that were injected with PBS. Blots are shown for the 7 day recovery. 


\section{Day Recovery}

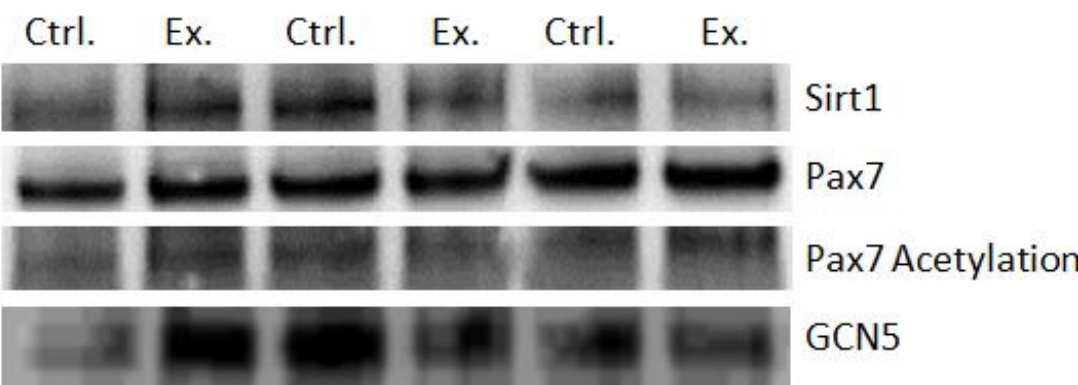

Appendix Figure 8: 14 Day Recovery Pax7 Protein Interaction
Figure 8: Pax7 Immunoprecipitation. Representative Western Blot images from the Pax7 pull-down and probed for Sirt1, Acetylation, and GCN5 are shown for experimental (Ex.) injured muscles that were injected with CTX, and the contralateral control (Ctrl.) muscles that were injected with PBS. Blots are shown for the 14 day recovery.

\section{Day Recovery}

Ctrl. Ex. Ctrl. Ex. Ctrl. Ex.

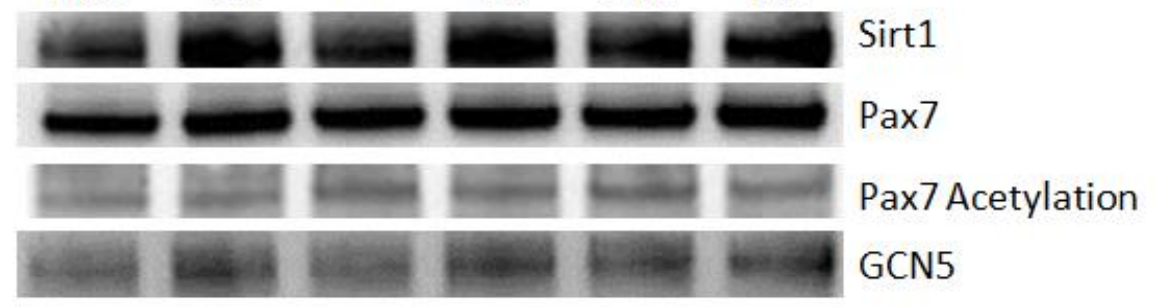

Figure 9: Pax7 Immunoprecipitation. Representative Western Blot images from the Pax7 pull-down and probed for Sirt1, Acetylation, and GCN5 are shown for experimental (Ex.) injured muscles that were injected with CTX, and the contralateral control (Ctrl.) muscles that were injected with PBS. Blots are shown for the 21 day recovery.

\section{Appendix Figure 9: 21 Day Recovery Pax7 Protein Interaction}

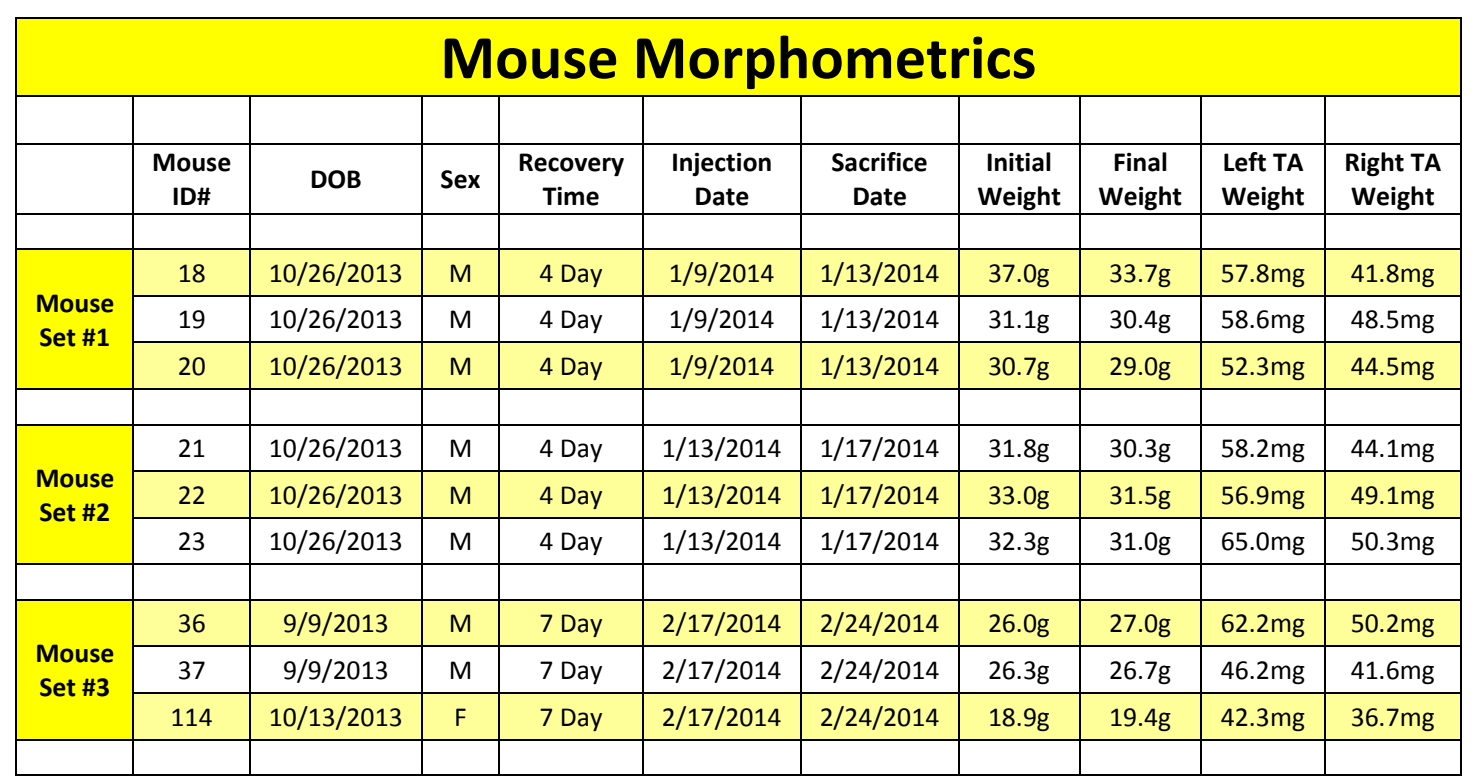




\begin{tabular}{|l|c|c|c|c|c|c|c|c|c|c|}
\multirow{4}{*}{$\begin{array}{c}\text { Mouse } \\
\text { Set \#4 }\end{array}$} & 117 & $10 / 13 / 2013$ & $\mathrm{~F}$ & 14 Day & $3 / 17 / 2014$ & $3 / 31 / 2014$ & $21.5 \mathrm{~g}$ & $23.3 \mathrm{~g}$ & $49.3 \mathrm{mg}$ & $40.4 \mathrm{mg}$ \\
\cline { 2 - 11 } & 118 & $10 / 13 / 2013$ & $\mathrm{M}$ & 14 Day & $3 / 17 / 2014$ & $3 / 31 / 2014$ & $33.9 \mathrm{~g}$ & $33.6 \mathrm{~g}$ & $58.1 \mathrm{mg}$ & $51.0 \mathrm{mg}$ \\
\hline & 119 & $10 / 13 / 2013$ & $\mathrm{M}$ & 14 Day & $3 / 17 / 2014$ & $3 / 31 / 2014$ & $28.5 \mathrm{~g}$ & $28.4 \mathrm{~g}$ & $53.5 \mathrm{mg}$ & $52.7 \mathrm{mg}$ \\
\hline & & & & & & & & & & \\
\hline \multirow{2}{*}{$\begin{array}{c}\text { Mouse } \\
\text { Set \#5 }\end{array}$} & 113 & $10 / 13 / 2013$ & $\mathrm{~F}$ & 21 Day & $2 / 17 / 2014$ & $3 / 10 / 2014$ & $18.5 \mathrm{~g}$ & $20.8 \mathrm{~g}$ & $43.7 \mathrm{mg}$ & $55.3 \mathrm{mg}$ \\
\cline { 2 - 11 } & 115 & $10 / 13 / 2013$ & $\mathrm{~F}$ & 21 Day & $2 / 17 / 2014$ & $3 / 10 / 2014$ & $22.2 \mathrm{~g}$ & $23.5 \mathrm{~g}$ & $49.4 \mathrm{mg}$ & $53.0 \mathrm{mg}$ \\
\cline { 2 - 12 } & $10 / 13 / 2013$ & $\mathrm{~F}$ & 21 Day & $2 / 17 / 2014$ & $3 / 10 / 2014$ & $20.9 \mathrm{~g}$ & $21.4 \mathrm{~g}$ & $47.1 \mathrm{mg}$ & $49.3 \mathrm{mg}$ \\
\hline
\end{tabular}

Appendix Table 1: Mouse Morphometrics

\section{Appendix B: Protocols \& Solutions}

\section{Homogenization Protocol}

Solutions \& Materials

1.) Homogenization Buffer (*per $1 \mathrm{~mL}$ of LB)

2.) $70 \%$ Ethanol

3.) $\mathrm{ddH}_{2} \mathrm{O}$

Procedure

\begin{tabular}{|l|}
\hline $10 \mu \mathrm{L}$ of Protease Inhibitor Cocktail \\
\hline $10 \mu \mathrm{L}$ of Phosphotase Inhibitor Cocktail II \& III \\
\hline $10 \mu \mathrm{L}$ of $\mathrm{NaVO}_{3}$ \\
\hline $10 \mu \mathrm{L}$ of PMSF \\
\hline $1 \mu \mathrm{L}$ of $1 \mathrm{M} \mathrm{DTT}$ \\
\hline
\end{tabular}

1.) Finely dice $\&$ mince muscle samples with razorblade on ice

2.) Add to $2 \mathrm{~mL}$ homogenization tube with $300 \mu \mathrm{L}$ of homogenization buffer

3.) Homogenize sample (drill press w/ ceramic tip) 30-50x or until complete

4.) Remove homogenate $\&$ place in $1.5 \mathrm{~mL}$ centrifuge tube on ice

5.) Clean ceramic tip \& homogenization tube with $70 \%$ ethanol (3-5x) \& $\mathrm{ddH}_{2} \mathrm{O}(5-7 \mathrm{x})$ before homogenizing next sample

6.) Repeat for all muscle samples

7.) Centrifuge all samples @ 10,000rpm for $10 \mathrm{~min}$ at $4^{\circ} \mathrm{C}$

8.) Collect supernate $\&$ place in new $1.5 \mathrm{~mL}$ centrifuge tube

a. Discard pellet

9.) Perform protein assay

\section{Coomassie Protein Assay}

Solutions \& Materials

1.) Protein Standards $(0 \mu \mathrm{g} / \mu \mathrm{L}-2,000 \mu \mathrm{g} / \mu \mathrm{L})$

a. Diluted in $\mathrm{ddH}_{2} \mathrm{O}$

2.) Protein homogenate

3.) 96-well plate

Procedure

1.) Add $5 \mu \mathrm{L}$ of protein standards \& protein homogenate to wells

a. Need duplicates

2.) Add $250 \mu \mathrm{L}$ of Coomassie Blue to the wells 
3.) Run through machine

\section{Preparing Loading Samples for Western Blot Analysis}

Solutions \& Materials

1.) Protein homogenate

2.) Lysis buffer

3.) $1 \mathrm{M} \mathrm{DTT}$

4.) $4 x$ loading dye

\begin{tabular}{|l|l|}
\hline \multirow{4}{*}{$1 \times$ Stock Cell Lysis Buffer $(250 \mathrm{~mL})$} & $226.25 \mathrm{~mL}$ of $\mathrm{ddH}_{2} \mathrm{O}$ \\
\cline { 2 - 2 } & $12.5 \mathrm{~g}$ of $1 \mathrm{M}$ Tris- $\mathrm{HCl}$ \\
\cline { 2 - 2 } & $7.5 \mathrm{~g}$ of NaCl \\
\cline { 2 - 2 } & $0.525 \mathrm{~g}$ of $\mathrm{NaF}$ \\
\hline & $1.25 \mathrm{~mL}$ of NP-40 \\
\hline
\end{tabular}

Procedure

1.) Obtain data from Coomassie Protein Assay

a. $50-75 \mu \mathrm{g} / \mu \mathrm{L}$

2.) Add appropriate amounts of samples \& solutions for $150 \mu \mathrm{L}$ of loading sample into $1.5 \mathrm{~mL}$ centrifuge tube \& vortex

a. $\mathrm{X} \mu \mathrm{L}$ of sample, $\mathrm{X} \mu \mathrm{L}$ of $\mathrm{LB}, 37.5 \mu \mathrm{L}$ of $4 \mathrm{x}$ loading dye, $7 \mu \mathrm{L}$ of $1 \mathrm{M}$ DTT

3.) Heat in the oven for $10 \mathrm{~min} @ 70^{\circ} \mathrm{C}$

4.) Cool to room temperature or store in $-20^{\circ} \mathrm{C}$

\section{Western Blot Protocol}

Solutions \& Materials

- 1x MES SDS Running Buffer (1L)

- Always make fresh

- 1x TG Transfer Buffer (1L)

○ Can be stored in $4^{\circ} \mathrm{C}$

- Loading Samples

- Protein Ladder

○ Novex Sharp Pre-stained Protein Ladder

- Antioxidant

- Ponceau Stain

- $2 \%$ Blocking Buffer

- TBST

- $4-12 \%$ Bis-Tris Premade Gel

- Nitrocellulose membrane 
- 4 Filter papers

- 4 Sponges

- Blot Module

○ Running \& Transfer

\begin{tabular}{|l|l|}
\hline \multirow{2}{*}{$1 \times$ MES SDS Running Buffer (1L) } & $950 \mathrm{~mL}$ of $\mathrm{ddH}_{2} \mathrm{O}$ \\
\cline { 2 - 2 } & $50 \mathrm{~mL}$ of $20 \times$ MES SDS Stock Running Buffer \\
\hline
\end{tabular}

\begin{tabular}{|l|l|}
\hline \multirow{4}{*}{$1 \times$ Transfer Buffer (1L) } & $750 \mathrm{~mL}$ of $\mathrm{ddH}_{2} \mathrm{O}$ \\
\cline { 2 - 2 } & $200 \mathrm{~mL}$ of Methanol \\
\cline { 2 - 2 } & $50 \mathrm{~mL}$ of $20 \times \mathrm{TG}$ Stock Transfer Buffer \\
\hline
\end{tabular}

\begin{tabular}{|l|l|}
\hline \multirow{2}{*}{$2 \%$ Blocking Solution $(50 \mathrm{~mL})$} & $50 \mathrm{~mL}$ of TBST \\
\cline { 2 - 2 } & $1 \mathrm{~g}$ of Smoke \\
\hline
\end{tabular}

\begin{tabular}{|l|l|}
\hline \multirow{3}{*}{$1 \times$ TBST (1L) } & $900 \mathrm{~mL}$ of $\mathrm{ddH}_{2} \mathrm{O}$ \\
\cline { 2 - 2 } & $100 \mathrm{~mL}$ of $10 \mathrm{x}$ TBS \\
\cline { 2 - 2 } & $500 \mu \mathrm{L}$ of Tween 20 \\
\hline
\end{tabular}

Procedure - Day 1

- Set up blot module with 1x MES SDS Running Buffer

- Wash wells of 4-12\% Bis-Tris Gel with the running buffer

- Must remove comb \& bottom sticker

- Fill blot module with running buffer so that the gel cassette is completely covered

- Lock cassette inside blot module

- Add $12-15 \mu \mathrm{L}$ of protein ladder in well(s)

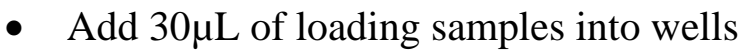

- Rungel a@ 200V until protein runs completely through gel

○ Set timer for 2.5hours

○ *Prep Steps*

○ $*$ Pre-soak 4 sponges, 4 filter papers, \& the nitrocellulose membrane in transfer buffer \& store in $4^{\circ} \mathrm{C}$ until needed*

* Remove cassette \& crack it open face down

* Carefully cut wells off of the top \& apply 2 filter papers to back of gel

* Turn cassette over so that the filter papers are in your hand \& push gel through followed by cutting off bottom gel strip

* Place gel \& filter paper in a box filled with pre-cooled transfer buffer \& place membrane on top

* Add 2 more filter papers on top of membrane \& smooth so that there are no bubbles

* Remove filter paper/membrane combo \& sandwich between the pre-soaked sponges inside the transfer module

* Fill center of transfer module with transfer buffer so that it is thoroughly soaked by locking \& unlocking the blot lock 
Fill outer compartment with pre-chilled $\left(4^{\circ} \mathrm{C}\right) \mathrm{ddH}_{2} \mathrm{O} \&$ add $500 \mu \mathrm{L}$ of antioxidant to center compartment

* Transfer in ice or $4^{\circ} \mathrm{C}$ cold room for 2:20hr @ 170mA

○ * Prep Steps*

○ *Make $50 \mathrm{~mL}$ of $2 \%$ Blocking Solution \& allow to stir for at least $30 \mathrm{~min} *$

- Remove membrane from module \& stain with Ponceau Stain for 10-15min

- Wash non-specific Poneceau Stain with $\mathrm{ddH}_{2} \mathrm{O}$ \& cut membrane for appropriate proteins

- Wash 3x5min in TBST

- Not including an initial wash \& toss

- Block membrane strips in 2\% Blocking Solution for 1 hour

- Separate membrane strips \& utilize blocking solution to create $1^{\circ}$ antibodies

$\circ$ Usually 1:1000 other than GAPDH (1:2000 or 1:5000 depending on strength)

- Rock membranes \& $1^{\circ}$ antibodies overnight at $4^{\circ} \mathrm{C}$

Procedure - Day 2

- *Prepare $2^{\circ}$ antibodies

○ 1:1000 dilution in 2\% Blocking Solution

- Collect $1^{\circ}$ antibodies \& store in $-20^{\circ} \mathrm{C}$

- Use no more than $5 \mathrm{x}$

- Wash membrane strips $3 \times 5 \mathrm{~min}$ in TBST

○ Not including an initial wash \& toss

- Incubate membrane strips in $2^{\circ}$ antibody on a rocker for 1 hour

- Collect $2^{\circ}$ antibodies \& store in $-20^{\circ} \mathrm{C}$

$\circ$ Use no more than $5 \mathrm{x}$

- Wash membrane strips $4 \times 15$ min in TBST

○ Not including an initial wash \& toss

○ *Prep steps*

- *Create appropriate ECL solutions (Pico, Dura, \& Femto) in a 1:1 ratio

* Dab membrane strips free of TBST \& process in the dark with the ECL

o Pico: 3-5min

○ Dura: $2.5 \mathrm{~min}$

○ Femto: $2.5 \mathrm{~min}$

* Dab membrane strips free of ECL \& place in cover sheet inside x-ray cassette \& take to imager

* If necessary, re-probe with ECL

○ Will need to was $3 \times 3 \mathrm{~min}$ in TBST prior to re-probing

Save membrane strips in TBST if necessary

\section{Immunoprecipitation Protocol}

\section{Solutions \& Materials}

- Protein homogenate 
- Protein A \& G magnetic beads

- Magnetic separator

- Tube rotator

- 1x Stock lysis buffer

- IP wash buffer

- $\mathrm{ddH}_{2} \mathrm{O}$

- Antibodies

- IP 1x elution buffer

\begin{tabular}{|l|l|}
\hline \multirow{4}{*}{$1 \times$ Stock Cell Lysis Buffer $(250 \mathrm{~mL})$} & $226.25 \mathrm{~mL}$ of $\mathrm{ddH}_{2} \mathrm{O}$ \\
\cline { 2 - 3 } & $12.5 \mathrm{~g}$ of $1 \mathrm{M} \mathrm{Tris}-\mathrm{HCl}$ \\
\cline { 2 - 3 } & $7.5 \mathrm{~g}$ of $\mathrm{NaCl}$ \\
\cline { 2 - 3 } & $0.525 \mathrm{~g}$ of $\mathrm{NaF}$ \\
\cline { 2 - 2 } & $1.25 \mathrm{~mL}$ of $\mathrm{NP}-40$ \\
\hline
\end{tabular}

\begin{tabular}{|l|l|}
\hline \multirow{2}{*}{ IP Wash Buffer $(50 \mathrm{~mL})$} & $50 \mathrm{~mL}$ of TBST \\
\cline { 2 - 2 } & $1.46 \mathrm{~g}$ of $\mathrm{NaCl}$ \\
\hline
\end{tabular}

IP 1x Elution Buffer $(30 \mu \mathrm{L})$

$21 \mu \mathrm{L}$ of LB $8 \mu \mathrm{L}$ of $4 \mathrm{x}$ Loading Dye

$2.8 \mu \mathrm{L}$ of $10 \mathrm{x}$ Reducing Agent

Procedure - Day 1

- Use $150-200 \mu \mathrm{g} / \mu \mathrm{L}$ protein homogenate per sample

- Obtained from Coomassie protein assay

- Separate $25 \mu \mathrm{L}$ of magnetic protein $\mathrm{A} / \mathrm{G}$ beads in magnetic separator \& discard supernate

○ No vortexing; finger flick only to avoid bead damage

- Add the protein homogenate to beads \& rotate @ $4^{\circ} \mathrm{C}$ for 1 hour to pre-clean the protein

* * Prep-step*

* Obtain new $1.5 \mathrm{~mL}$ tubes for corresponding samples \& bring total volume (including current pre-cleaning protein) to $500 \mu \mathrm{L}$ with $1 \mathrm{x}$ lysis buffer \& $10 \mu \mathrm{L}$ of pull-down antibody*

- Separate protein from beads in the magnetic separator \& add supernate to the prep-step tubes

$\circ$ Antigen + antibody $=$ new tubes

- Discard the tubes with the beads

- Rotate antigen \& antibody mixture @ $4^{\circ} \mathrm{C}$ for 2 hours

* *Prep-step*

* *Pre-clean $25 \mu \mathrm{L}$ of new protein A/G beads for each sample with IP wash buffer*

$\circ 1^{\text {st }}$ wash $-200 \mu \mathrm{L}$ for $3 \mathrm{~min}$

$\circ 2^{\text {nd }}$ wash $-500 \mu \mathrm{L}$ for $3 \mathrm{~min}$

$\circ 3^{\text {rd }}$ wash $-500 \mu \mathrm{L}$ for $3 \mathrm{~min}$

- Combine antigen $\&$ antibody with new pre-cleaned magnetic $\mathrm{A} / \mathrm{G}$ beads $\&$ rotate $@ 4^{\circ} \mathrm{C}$ overnight 
Procedure - Day 2

* *rep-step*

* *Turn oven on to $70^{\circ} \mathrm{C}^{*}$

- Collect beads with magnetic separator \& discard the supernate

- Wash beads with $500 \mu \mathrm{L}$ of IP wash buffer $3 \times 1.5 \mathrm{~min}$

- Wash beads with $500 \mu \mathrm{L}$ of $\mathrm{ddH}_{2} \mathrm{O}$ for $1.5 \mathrm{~min}$

- Add $30 \mu \mathrm{L}$ of IP 1x elution buffer to each sample

- Heat samples @ $70^{\circ} \mathrm{C}$ for $10 \mathrm{~min}$

$\circ$ Only if $\varnothing$ rabbit antibody

- Remove beads \& save supernate

- Allow to cool to room temperature or store @ - $-20^{\circ} \mathrm{C}$

- Run as a normal Western Blot

\section{Membrane Stripping Protocol}

Solutions \& Materials

- Membrane strips

- Oven w/ rotator

- Stripping Buffer

- 1x TBST

- $2 \%$ Blocking Solution

\begin{tabular}{|l|l|}
\hline \multirow{4}{*}{ Stripping Buffer $(100 \mathrm{~mL})$} & $100 \mathrm{~mL} \mathrm{ddH} \mathrm{O}_{2}$ \\
\cline { 2 - 2 } & $0.699 \mathrm{~mL}$ of $100 \mathrm{mM}$ 2-Mercaptoethanol \\
\cline { 2 - 2 } & $2 \mathrm{~g}$ of $2 \% \mathrm{SDS}$ \\
\cline { 2 - 2 } & $0.985 \mathrm{~g}$ of Tris-HCl \\
\hline
\end{tabular}

2\% Blocking Solution ( $50 \mathrm{~mL})$

$50 \mathrm{~mL}$ of TBST

$1 \mathrm{~g}$ of Smoke

$900 \mathrm{~mL}$ of $\mathrm{ddH}_{2} \mathrm{O}$

1x TBST (1L)

$100 \mathrm{~mL}$ of $10 x$ TBS

$500 \mu \mathrm{L}$ of Tween 20

Procedure:

*Prep-Steps*

- Make appropriate amount of $2 \%$ Blocking Solution \& allow to stir for 30min

- Pre-warm $50 \mathrm{~mL}$ of Stripping Buffer in the oven @ $55^{\circ} \mathrm{C}$ for $30 \mathrm{~min}$ with rotation

- Place all membranes in Stripping Buffer \& rotate @ $55^{\circ} \mathrm{C}$ for $10 \mathrm{~min}$

- Remove membrane strips \& wash 3x5min in 1x TBST

$\circ$ Can reuse Stripping buffer $5 \mathrm{x}$

- Block membrane strips for $30 \mathrm{~min}$ in $2 \%$ Blocking Solution 
- Add primary antibodies \& rock overnight @ $4^{\circ} \mathrm{C}$

- Continue with day 2 of Western Blot Protocol

\section{Immunohistochemisrty Protocol}

Solutions \& Materials

- Tissue sections

- 1x PBS

- IHC blocking buffer

- IHC formaldehyde fixing solution

- IHC antibody dilution buffer

- 3 covered glass Coplin jars

- Pap-pen or wax pencil

\begin{tabular}{|l|l|}
\hline \multirow{2}{*}{$1 \times$ PBS (1L) } & $900 \mathrm{~mL}$ of $\mathrm{ddH}_{2} \mathrm{O}$ \\
\cline { 2 - 2 } & $100 \mathrm{~mL}$ of $10 \times \mathrm{PBS}$ \\
\hline
\end{tabular}

IHC 4\% Formaldehyde Fixing Solution $(200 \mathrm{~mL})$

$200 \mathrm{~mL}$ of $1 x$ PBS

$8 \mathrm{~g}$ of Paraformaldehyde

IHC Blocking Buffer (10mL)

$9 \mathrm{~mL}$ of $1 x$ PBS

$500 \mu \mathrm{L}$ of Normal Serum (same animal as $2^{\circ}$ )

$30 \mu \mathrm{L}$ of Triton X-100 (last \& while stirring)

IHC Antibody Dilution Buffer (10mL)

$10 \mathrm{~mL}$ of $1 \mathrm{x}$ PBS

$30 \mu \mathrm{L}$ of Triton $\mathrm{X}-100$

$0.1 \mathrm{~g}$ of BSA (last)

Procedure - Day 1

* *Prep-step*

* *Make $200 \mathrm{~mL}$ of IHC $4 \%$ formaldehyde fixing solution on warm hot plate while stirring*

*Warm tissue sections to room temperature*

- Fix tissue sections (on slides) in paraformaldehyde-specific Coplin jar for $15 \mathrm{~min}$

- Wash slides $3 \times 5 \mathrm{~min}$ in $1 \times$ PBS

- Store IHC $4 \%$ formaldehyde fixing solution in $4^{\circ} \mathrm{C}$

- Can store in $4^{\circ} \mathrm{C}$ for 1 week

- Alternate between 2 Coplin jars with 1x PBS already inside to avoid washing off tissue sections

*Prep-step*

* *Make fresh IHC blocking buffer*

- Block slide for 1hour in IHC blocking buffer

○ Make fresh every time - do not store 
*Prep-step*

*Make fresh IHC antibody dilution buffer*

*Add primary antibody(s) to IHC antibody dilution buffer*

○ Can store IHC dilution buffer in $4^{\circ} \mathrm{C}$ for 1 week

- Remove blocking solution carefully with kimwipe \& place slides flat on soaked sponge in box with $\mathrm{H}_{2} \mathrm{O}$ to keep slides hydrated

- Do not touch tissue sections with kimwipe

- $\quad$ Ring sections with pap-pen or wax pencil \& apply $50 \mu \mathrm{L}$ of $1^{\circ}$ antibody(s)

- Incubate@ $4^{\circ} \mathrm{C}$ in dark box overnight with lid to prevent evaporation

Procedure - Day 2

- Wash slides $3 \times 5 \mathrm{~min}$ in $1 \times$ PBS

O Alternate Coplin jars to avoid washing off tissues

*Prep-step*

* *Go to complete dark area - absolutely no light*

*Make fresh IHC antibody dilution buffer with fluorochrome-conjugated $2^{\circ}$ antibody*

- Remove excess 1x PBS from slides \& place in dark \& covered box with soaked sponges with $\mathrm{H}_{2} \mathrm{O}$ in bottom

- Make sure the slides are level

- Incubate slide in $50 \mu \mathrm{L}$ of $2^{\circ}$ antibody for 1-2hours @ room temperature

- Rinse 3x5min in $1 x$ PBS

- Remove excess 1x PBS with kimwipe

- Add 1 drop of DAPI to each tissue section \& carefully add coverslip

- Incubate overnight \& store in $4^{\circ} \mathrm{C}$

\begin{tabular}{|c|c|}
\hline Solution & Components \\
\hline \multirow{3}{*}{ 1x TBST (1L) } & $900 \mathrm{~mL}$ of $\mathrm{ddH}_{2} \mathrm{O}$ \\
\hline & $100 \mathrm{~mL}$ of $10 x$ TBS \\
\hline & $500 \mu \mathrm{L}$ of Tween 20 \\
\hline \multirow{2}{*}{ 1x PBS (1L) } & $900 \mathrm{~mL}$ of $\mathrm{ddH}_{2} \mathrm{O}$ \\
\hline & $100 \mathrm{~mL}$ of $10 x$ PBS \\
\hline \multirow{2}{*}{ 1x MES SDS Running Buffer (1L) } & $950 \mathrm{~mL}$ of $\mathrm{dd}_{2} \mathrm{O}$ \\
\hline & $50 \mathrm{~mL}$ of $20 x$ MES SDS Stock Running Buffer \\
\hline \multirow{3}{*}{ 1x Transfer Buffer (1L) } & $750 \mathrm{~mL}$ of $\mathrm{ddH}_{2} \mathrm{O}$ \\
\hline & $200 \mathrm{~mL}$ of Methanol \\
\hline & $50 \mathrm{~mL}$ of 20x TG Stock Transfer Buffer \\
\hline \multirow{2}{*}{ 1x Stock Cell Lysis Buffer $(250 \mathrm{~mL})$} & $226.25 \mathrm{~mL}$ of $\mathrm{dd}_{2} \mathrm{O}$ \\
\hline & $12.5 \mathrm{~g}$ of $1 \mathrm{M}$ Tris- $\mathrm{HCl}$ \\
\hline
\end{tabular}




\begin{tabular}{|c|c|}
\hline & $7.5 \mathrm{~g}$ of $\mathrm{NaCl}$ \\
\hline & $0.525 \mathrm{~g}$ of $\mathrm{NaF}$ \\
\hline & $1.25 \mathrm{~mL}$ of NP-40 \\
\hline \multirow{5}{*}{ Homogenization Buffer ( ${ }^{*}$ All are per $1 \mathrm{~mL} \mathrm{LB}^{*}$ ) } & $10 \mu \mathrm{L}$ of Protease Inhibitor Cocktail \\
\hline & $10 \mu \mathrm{L}$ of Phosphotase Inhibitor Cocktail II \& III \\
\hline & $10 \mu \mathrm{L}$ of $\mathrm{NaVO}_{3}$ \\
\hline & $10 \mu \mathrm{L}$ of PMSF \\
\hline & $1 \mu \mathrm{L}$ of $1 \mathrm{M} \mathrm{DTT}$ \\
\hline \multirow{2}{*}{ 2\% Blocking Solution (50mL) } & $50 \mathrm{~mL}$ of TBST \\
\hline & $1 \mathrm{~g}$ of Advanced ECL Blocking Reagent \\
\hline \multirow{4}{*}{ Stripping Buffer (100mL) } & $100 \mathrm{~mL} d d \mathrm{H}_{2} \mathrm{O}$ \\
\hline & $0.699 \mathrm{~mL}$ of $100 \mathrm{mM}$ 2-Mercaptoethanol \\
\hline & $2 \mathrm{~g}$ of $2 \%$ SDS \\
\hline & $0.985 \mathrm{~g}$ of Tris- $\mathrm{HCl}$ \\
\hline \multirow{3}{*}{ IP 1x Elution Buffer $(30 \mu \mathrm{L})$} & $21 \mu \mathrm{L}$ of $\mathrm{LB}$ \\
\hline & $8 \mu \mathrm{L}$ of $4 \mathrm{x}$ Loading Dye \\
\hline & $2.8 \mu \mathrm{L}$ of $10 x$ Reducing Agent \\
\hline \multirow{2}{*}{ IP Wash Buffer (50mL) } & $50 \mathrm{~mL}$ of TBST \\
\hline & $1.46 \mathrm{~g}$ of $\mathrm{NaCl}$ \\
\hline \multirow{3}{*}{ Cell Culture Digestion Solution I (18mL) } & $16.2 \mathrm{~mL}$ of $\mathrm{F} 10$ \\
\hline & $1.8 \mathrm{~mL}$ of Heart Serum \\
\hline & $26.82 \mathrm{mg}$ of Collagenase II \\
\hline \multirow{4}{*}{ Cell Culture Digestion Solution II (18mL) } & $16.2 \mathrm{~mL}$ of $\mathrm{F} 10$ \\
\hline & $1.8 \mathrm{~mL}$ of Heart Serum \\
\hline & $5.4 \mathrm{mg}$ of Collagenase II \\
\hline & $18 \mathrm{U}$ of Dispase II \\
\hline \multirow{3}{*}{ IHC Blocking Buffer (10mL) } & $9 \mathrm{~mL}$ of $1 \mathrm{x}$ PBS \\
\hline & $500 \mu \mathrm{L}$ of Normal Serum (same animal as $2^{\circ}$ ) \\
\hline & $30 \mu \mathrm{L}$ of Triton X-100 (last \& while stirring) \\
\hline \multirow{3}{*}{ IHC Antibody Dilution Buffer (10mL) } & $10 \mathrm{~mL}$ of $1 \times$ PBS \\
\hline & $30 \mu \mathrm{L}$ of Triton $\mathrm{X}-100$ \\
\hline & $0.1 \mathrm{~g}$ of BSA (last) \\
\hline \multirow{2}{*}{ IHC 4\% Formaldehyde Fixing Solution $(200 \mathrm{~mL})$} & $160 \mathrm{~mL}$ or $200 \mathrm{~mL}$ of $1 \times$ PBS \\
\hline & $40 \mathrm{~mL}$ of Formaldehyde or $8 \mathrm{~g}$ of Paraformaldehyde \\
\hline
\end{tabular}

